\title{
BUOYANCY CONTROL AS A FUNCTION OF THE SPERMACETI ORGAN IN THE SPERM WHALE
}

\author{
MALCOLM R. CLARKE
}

The Laboratory, Marine Biological Association, Citadel Hill, Plymouth

(Figs. 1-10)

Abstract

Introduction.

Material and methods .

Observations

Distribution and behaviour

Buoyancy

Effect of sea-water temperature and density .

Effect of pressure on tissues

Liquid part of tissues

Solid part of tissues

Effect of pressure on lung gas

Buoyancy of the whale when on the surface

Buoyancy of the whale over its range

Control of buoyancy

The change in temperature of spermaceti oil necessary to achieve neutral buoyancy

The loss of heat from the spermaceti oil necessary to achieve neutral buoyancy

The mechanism of losing heat

Heat loss via the surface of the head

Heat loss via the right naris

The time required for heat exchange

Heat available for reheating the spermaceti oil

Storage of heat

Timing of heat loss

General pattern .

Vasoconstriction and vasodilation

Centre of gravity

'Popping up' and 'extra' buoyancy

Size of whale

Discussion

General conclusions .

Criticism of the buoyancy control hypothesis

Compatibility with other theories

Appendix I. Temperature of the blubber

Appendix II. Conductivity of whale tissues .

Appendix III. Temperature of spermaceti oil

Appendix IV. Sea water in the naris

Appendix V. Heat transfer

References 
Factors influencing buoyancy of the sperm whale throughout its geographical and depth ranges are discussed and the effects of variation in sea-water density, the volume of air in its lungs and the effect of pressure on its tissues are analysed. It is shown that by dropping the temperature of spermaceti oil in its head by about $3{ }^{\circ} \mathrm{C}$ the whale could make itself neutrally buoyant at its operational depths deeper than $200 \mathrm{~m}$ over its whole geographical range. It is shown that sufficient heat could be lost in the time available and alternative mechanisms for this are described and discussed. Sufficient heat is available to the whale in a diving cycle for re-heating the oil. This hypothesis of buoyancy control accounts for many of the unusual features of the sperm whale such as general and detailed structure of the snout, thermal properties of the spermaceti oil, the volumes and dimensions of the oil and nares, the whale's buoyancy at the sea surface and the temperature of the oil when at the sea surface.

\section{INTRODUCTION}

This paper will discuss the buoyancy of the sperm whale throughout its range and show that the whale probably has some control over its own buoyancy. Evidence will then be presented in support of the hypothesis that the whale can attain neutral buoyancy at depths greater than $200 \mathrm{~m}$ by control of the temperature of the spermaceti oil in its head. As a basis for this, papers describing the detailed structure and proportions of the whale (Clarke, 1978a) and some physical properties of spermaceti oil (Clarke, 1978b) have already been published.

Here, a short description of the whale's behaviour and geographical depth distribution is followed by a summary of the changes in ambient conditions it will experience and the effect these will have upon its buoyancy. The hypothesis suggesting buoyancy control by the spermaceti organ will then be considered in detail. First, it will be shown that by dropping the temperature of the spermaceti oil from $33^{\circ} \mathrm{C}$, its temperature when the whale is at the surface, to about $30^{\circ} \mathrm{C}$ the increase in density is such that the whale can become neutrally buoyant anywhere in its geographical range at depths greater than $200 \mathrm{~m}$. Secondly, it is shown that the quantity of heat which must be lost to achieve this can be lost in the time available and the mechanism for doing this is discussed. Thirdly, the amount of heat available to the whale during a dive cycle is shown to be sufficient to reheat the spermaceti oil to $33^{\circ} \mathrm{C}$. Finally, the timing of heat exchange and the advantages the whale gains from the mechanism, including those concerning body heat regulation, are discussed.

While many functions have been proposed for the spermaceti organ (see Clarke, 1978 a) its use as a buoyancy organ does not necessarily exclude other functions and they need not be considered in detail here except where proposed mechanisms clash with the buoyancy function (see Discussion). When buoyancy has been proposed previously as a possible function of the organ, few or no details of structure, physical properties or mechanism have been considered.

\section{MATERIAL AND METHODS}

Observations on the diving and surface behaviour of living sperm whales were made from spotter aircraft and from whale catchers operating from Durban and in the Antarctic. Cine film made during these excursions have helped in particular with estimating buoyancy of the whale immediately after capture. The temperature of different tissues (Appendix III) of the whale immediately after capture was determined by means of $1 \mathrm{~m}$ long, multi-thermistor, pointed 
probes which were pushed into the whales, sometimes with the help of a spear. Such probes contained up to six calibrated thermistors and were also used together with calibrated $40{ }^{\circ} \mathrm{C}$ thermometers at the whaling station. Temperatures were also taken by Dr P. Best and Dr R. Gambell at my request during later whaling seasons.

In the consideration of buoyancy and control a 30 -tonne whale will be used as an example.

\section{OBSERVATIONS}

\section{Distribution and behaviour}

Sperm whales are unusual, but not unique, among Odontocetes in having a worldwide distribution. During previous centuries, sailing ships sought and caught them in every ocean from $60^{\circ} \mathrm{N}$ to $40^{\circ} \mathrm{S}$ (Townsend, 1932) and, since the development of modern techniques, pelagic fleets have extended the pursuit to the Antarctic. The species was of particular importance to industry when it was largely based upon capture by hand harpoons used from small boats, because only whales which float when killed can be handled from such vessels (Beale, 1838). This characteristic of sperm whales was shared by the mystacocete right whales, which were fished to near extinction. Large-scale killing of the rorquals, including the blue, fin and sei whales, had to await the advent of larger ships with more buoyancy, steam winches and compressed air to pump into the carcasses so that they would float. The distribution of female sperm whales, which grow to a maximum length of about $38 \mathrm{ft}(11.6 \mathrm{~m})$, and of calves less than $38 \mathrm{ft}(11.6 \mathrm{~m})$ in length, is limited to waters north of $40^{\circ} \mathrm{S}$, while the large males, which can grow to a maximum of at least $55 \mathrm{ft}$ (Beddard, 1915, p. 201 ; Beale, 1838, p. 15), are distributed from the equator to high latitudes of the Antarctic. These large males migrate to and fro between cold and warm water (Clarke, 1978c).

Sperm whales eat cephalopods almost exclusively and have a very characteristic diving pattern during feeding (Beale, 1838, p. 42; Caldwell, Caldwell \& Rice, 1966). Generally, adult males dive for approximately $50 \mathrm{~min}$, and take 50-60 breaths lasting a period of $10 \mathrm{~min}$ before the next dive. This whole cycle may be repeated without break throughout daylight hours (Beale, 1838). Females and calves tend to stay down a shorter period. Longer dives have been observed and I have described the dives of two bulls which were almost certainly down for 82 and $83 \mathrm{~min}$, although they may have been down for 53 and 112 min respectively, depending on whether or not they changed positions while submerged (Clarke, 1976). The long duration of the normal dive explains the high myoglobin content of the swimming muscles and their very dark red to black coloration (Scholander, 1940).

The depth to which sperm whales dive during these long feeding excursions can be deduced from the amount of rope paid out during a dive after the whale is harpooned (Beale, 1838, p. 161), the records of sonar operators on board whale-catchers (Lockyer, 1977), the depth at which sperm whales have become tangled with telephone cables (Heezen, 1957), the known distribution of organisms in their stomachs at capture (Clarke, 1976) and in other ways (Whitney, quoted by Norris \& Harvey, 1972). From these various lines of evidence, it is clear that large sperm whales frequently dive deeper than $1000 \mathrm{~m}$, and occasionally dive to much greater depths (e.g. $2250 \mathrm{~m}$ quoted by Norris \& Harvey, 1972). 
At first sight, observations of dives using sonar on whale-catchers (Lockyer, 1977) and three-dimensional hydrophone arrays (Watkins \& Schevill, 1977) appear to conflict with the long-established belief of whalers that when sperm whales 'sound' and go deep they usually surface again within a few hundred meters of the position of submergence. When these whales lift their tails clear of the water and 'sound' after the breathing cycle at the surface, pursuing whalers usually stop and wait for them to surface again close by. This has been common practice in open-boat whaling (Beale, 1838; Hopkins, 1922) for centuries and also when modern catchers are not employing sonar for tracking the whales underwater. When sonar is used the whales often move along underwater at shallower depths $(<500 \mathrm{~m})$ and many whalers believe the whales are driven away by the sonar. The observation by Watkins \& Schevill (1972) that a sound source used to calibrate their hydrophones caused the sperm whales under observation to stop emitting signals shows how sensitive whales are to underwater sounds. Certainly my own observations from the air off Durban suggest that approaching catchers can be detected by whales when over six miles distant; for example, on 30 August 1969 a large school of sperm whales showed no sign of alarm until a catcher approached to $7-8$ miles distant when they increased speed, turned away from the catcher and many whales repeatedly jumped almost clear of the water; many also banged their tails down on to the surface of the water. This behaviour certainly appeared to be a result of the catcher's presence and again illustrates the awareness the whales have of pursuing ships and underwater sounds. Thus, observations from moving ships, and particularly if they have sonar, are likely to elicit unusual diving patterns in the whales. While observations with hydrophone arrays suggest that whales may travel laterally during a dive and surface considerable distances away from their point of submergence, the common experience of whalers and my own observations on several occasions (e.g. Clarke, 1976) show that not infrequently the whales surface near to their point of submergence. That this is not unusual is extremely important, since it suggests that the whales sometimes move very little laterally and must lie almost still in the water at depth. To lie still in water may have considerable advantage in detection and capture of prey, but it can only be achieved by the animal being very nearly neutrally buoyant. By replacing sodium ions by ammonium ions and by storing fats, many fish and cephalopods achieve a buoyancy within $0.002 \%$ of their body weight (Denton, 1974; Gilpin-Brown, Denton \& Clarke, 1978). Old classes of submarine displacing 1600-2000 tons needed to control buoyancy to within about 401 of water when they required to lie still in the water for listening purposes. This represents $0.002-0.003 \%$ of their displacement weight.

Over the geographical and depth range of the whale, the ambient density of the water changes and the whale needs to control its own buoyancy within fine limits in order to lie still in mid-water.

\section{Buoyancy}

Factors influencing buoyancy of the sperm whale are the ambient sea water density, the effect of pressure on both liquid and solid components of the tissues and the effect of pressure on lung volume. Variation of these factors all follow physical laws and their effect for a particular size of whale can be calculated. Accuracy of computation depends upon the accuracy of estimates of the proportion of liquid, solid and air in a whale of a 
particular weight. Such estimates are based upon very few measurements of Cetacea. Upper and lower limits are given for these factors but calculations are made from middle values considered most likely.

Another requirement in buoyancy calculations is a knowledge of buoyancy at some particular location in the whale's range. This has not yet been measured accurately but an estimate has been made for whales observed floating immediately after death.

Errors in these various estimates are not likely to be sufficient to invalidate the hypothesis presented here but it must be recognized that doubt does exist in the actual numbers presented, particularly as there must be variation between individual whales of the same weight.

Effect of sea-water temperature and density

In moving between the Equator and the high Antarctic at the sea surface, a whale experiences a change in surface water temperature of as much as $26^{\circ} \mathrm{C}$. If it dives to $1000 \mathrm{~m}$ on the Equator, the change may be as much as $23^{\circ} \mathrm{C}$. Both these changes in

Table 1. Temperature, salinity and density of water at selected depths at a position on the Equator ('Crawford' Sta. 498, $00^{\circ} 15^{\prime} S, 29^{\circ} \mathrm{W}$ from Fuglister, 1960) and a position in the Antarctic ('Meteor' Sta. 125, 54 59' S, $8^{\circ} 58^{\prime}$ E 17 Feb. 26 Wüst, 1932).

Densities are given at both surface pressure and in situ pressures.

\begin{tabular}{|c|c|c|c|c|c|c|c|c|c|}
\hline \multirow{2}{*}{$\begin{array}{l}\text { Depth } \\
\text { (m) }\end{array}$} & \multicolumn{2}{|c|}{$\mathrm{T}\left({ }^{\circ} \mathrm{C}\right)$} & \multicolumn{2}{|c|}{ Salinity $(\% 0)$} & \multicolumn{2}{|c|}{$\begin{array}{l}\text { Density of water at } \\
\text { surface pressure }\end{array}$} & \multicolumn{2}{|c|}{$\begin{array}{l}\text { Density of water } \\
\text { at depth }\end{array}$} & \multirow{2}{*}{$\begin{array}{c}\text { Pressure } \\
\text { effect on } \\
\text { density }\end{array}$} \\
\hline & Equator & $55^{\circ} \mathrm{S}$ & Equator & $55^{\circ} \mathrm{S}$ & Equator & $55^{\circ} \mathrm{S}$ & Equator & $55^{\circ} \mathrm{S}$ & \\
\hline 0 & 26.96 & $1 \cdot 51$ & 36.091 & 33.75 & 1.023528 & 1.02703 & 1.02353 & 1.02703 & - \\
\hline $120 / 100$ * & $22 \cdot 77$ & -0.58 & $36 \cdot 234$ & 33.79 & 1.024797 & 1.02718 & 1.02524 & 1.02771 & 0.0004 \\
\hline 200 & $13 \cdot 13$ & $1 \cdot 30$ & $35 \cdot 298$ & $34 \cdot 33$ & 1.026617 & 1.02751 & 1.02752 & 1.02844 & 0.0009 \\
\hline 500 & $6 \cdot 38$ & 1.95 & 34.542 & 34.60 & 1.027165 & 1.02768 & 1.02945 & 1.03010 & 0.0023 \\
\hline 1000 & $4 \cdot 34$ & $1 \cdot 78$ & 34.597 & $34 \cdot 72$ & 1.027450 & 1.02778 & 1.03207 & 1.03247 & 0.0046 \\
\hline 1500 & $4 \cdot 15$ & $1 \cdot 14$ & 34.967 & 3471 & 1.027767 & 1.02783 & 1.03465 & 1.03483 & 0.0069 \\
\hline 2000 & $3 \cdot 47$ & 0.74 & $34 \cdot 974$ & 34.68 & 1.027841 & 1.02783 & 1.03700 & 1.03714 & 0.0092 \\
\hline
\end{tabular}

ambient temperature are accompanied by changes in the density of the ambient sea water, which is mainly dependent upon temperature, although salinity and pressure also play a small part. To show extreme ambient conditions of water temperature and density which a large sperm whale will encounter during migration and diving, two stations have been selected for Table 1. The Crawford station, close to the Equator, was taken as an example in which surface temperatures are very high but is not exceptional, and slightly greater extremes could probably be found at other localities and seasons.

If a 30-tonne ( $44 \mathrm{ft}, 13.4 \mathrm{~m}$ ) whale is taken as an average male adult, the effect of the density of the water upon lift or downthrust experienced by the whale, ignoring effects of lung gas, compression of the flesh and ambient sea water and possible adjustments of fat in the whale, can be readily determined. If, for example, the whale is neutrally buoyant at the surface on the Equator and moves to $55^{\circ} \mathrm{S}$, it will then experience a lift of approximately

$$
(1.02703-1.02353) \times 30000=105 \mathrm{~kg} \text {. }
$$


Conversely, if it is neutrally buoyant in the Antarctic and moves to the Equator, it will experience a downthrust of $105 \mathrm{~kg}$. During a dive, the whale would experience increased lift resulting from increase in water density whether it dives at the Equator or at $55^{\circ} \mathrm{S}$. Table 2 shows the increase in lift the whale, neutrally buoyant at the surface, would experience during a descent at the two selected stations as a result of change in the seawater density excluding the effect of pressure. From this table it can be seen that the biggest change would take place between 100 and $200 \mathrm{~m}$. At $55^{\circ} \mathrm{S}$ the magnitude of the change in lift is much less $(19 \%)$ than on the Equator.

Thus, during migration and diving, the whale would vary considerably in buoyancy if no factors other than sea-water density (without the pressure effect) were involved. However, two other factors are involved, one of considerable importance.

Table 2. Change in lift (in $\mathrm{kg}$ ) of a 30-tonne whale resulting from change in ambient seawater density if it were neutrally buoyant at the surface (compression of contained air, flesh and sea water is excluded)

\begin{tabular}{|c|c|c|c|c|c|c|}
\hline \multirow[b]{3}{*}{ Depth (m) } & \multicolumn{3}{|c|}{ Equator } & \multicolumn{3}{|c|}{$55^{\circ} \mathrm{S}$} \\
\hline & \multirow[b]{2}{*}{$\mathrm{kg}$} & \multicolumn{2}{|c|}{$\%$ change from: } & \multirow[b]{2}{*}{$\mathrm{kg}$} & \multicolumn{2}{|c|}{$\%$ change from } \\
\hline & & Om & $\begin{array}{l}\text { Depth } \\
\text { above }\end{array}$ & & Om & $\begin{array}{l}\text { Depth } \\
\text { above }\end{array}$ \\
\hline 100 & 38 & 29 & 29 & 5 & 21 & 21 \\
\hline 200 & 92 & 71 & 42 & 14 & 58 & 37 \\
\hline 500 & 109 & 84 & 13 & 20 & 83 & 25 \\
\hline 1000 & 118 & 91 & 7 & 23 & 95 & 12 \\
\hline 1500 & 127 & 98 & 6 & 24 & 100 & 5 \\
\hline 2000 & 129 & 100 & 2 & 24 & 100 & 0 \\
\hline
\end{tabular}

\section{Effect of pressure on tissues}

Liquid part of tissues. During a dive the pressure acting upon the whale will decrease its volume by compressing water and liquid fat in its body. As the water, which usually comprises $50-60 \%$ of the body weight in adult mammals (Altmann \& Dittmar, 1968), is compressed to about the same extent as the ambient sea water, its compression will have very little effect on the buoyancy of the whale and can be disregarded here. The fat, however, will be compressed to a greater extent than the ambient sea water and this will tend to reduce the whale's buoyancy as it dives deeper.

Taking the example of a 30 -tonne whale, the total oil will weigh about $7300 \mathrm{~kg}$. When at the sea surface the temperature of the blubber oil is probably near $29^{\circ} \mathrm{C}$ (Appendix I) and that of the spermaceti oil is near $33^{\circ} \mathrm{C}$ (Appendix III). At these temperatures all of the oil is liquid. From an experiment with spermaceti oil (Clarke, 1978b), an increase in pressure, without a change in temperature, would increase the density of the oil relative to the ambient sea-water density by an amount determined by its initial temperature. It is likely that the blubber oil at $29^{\circ} \mathrm{C}$ increases in density to approximately the same extent with increasing pressure as does spermaceti oil at $33^{\circ} \mathrm{C}$ (at which temperature the latter is liquid). This increase in relative density if the whale dives to $1000 \mathrm{~m}$ will be

$$
7300 \times(0.8625-0.8560)=47 \mathrm{~kg},
$$


and, taking into account the increase in sea-water density with pressure (i.e. 0.0046 at $1000 \mathrm{~m})$, the decrease in lift would be $13 \mathrm{~kg}$.

However, oil increases in temperature with increase in pressure (Clarke, 1978b) and the effect of this on density must also be considered.

The effect of rise in temperature of the oil as the whale dives is important in two respects. First, in considering buoyancy, if the heat produced by pressure increase cannot escape it will make the oil less dense. This need not be considered for the spermaceti oil since its temperature is under control (according to the function proposed here) and the initial and final densities of the spermaceti oil are all that need concern us. However, the blubber oil may not be controlled in the same way because its temperature is linked to loss of heat from the whale and the temperature effect on its density must be considered. Secondly, in considering the heat loss from the spermaceti oil, this rise in temperature must be taken into account (see later).

The blubber acts as an insulation between the tissues immediately below it at $32-37^{\circ} \mathrm{C}$ and the water at $4{ }^{\circ} \mathrm{C}$ (at $1000 \mathrm{~m}$ on the Equator). The blubber oil, however, might be expected to lose heat to the cold water at depth. The large surface area, which, in a $44 \mathrm{ft}$ $(13.4 \mathrm{~m})$ whale, equals $69.3 \mathrm{~m}^{2}\left(74 \mathrm{~m}^{2}\right.$ including flippers and flukes) (Clarke 1978a), and the low ambient water temperature would facilitate cooling. The rate of cooling by conduction can be calculated from

$$
Q=\frac{K A\left(t_{1}-t_{2}\right) T}{d}
$$

where $Q=$ calories conducted, $K=$ thermal conductivity of blubber or $0.0005 \mathrm{~g}$ $\mathrm{cal} / \mathrm{cm}^{2} /{ }^{\circ} \mathrm{C} / \mathrm{cm} / \mathrm{s}$ (Parry, 1949), $A=$ area of blubber in $\mathrm{cm}^{2}, t_{1}-t_{2}$ - difference in temperature between blubber and water, $T=$ time in seconds and $d=$ mean distance from the centre of blubber to the body surface in $\mathrm{cm}(8.5 \mathrm{~cm}$ for $14 \mathrm{~m}$ whale, Clarke, $1978 a)$.

If we take the temperature of the blubber to be maintained at $29{ }^{\circ} \mathrm{C}$ (approximately that found by Best after an 11 min dive, Appendix I), the ambient water temperature at depth as $4{ }^{\circ} \mathrm{C}$ (Table 1 ), and the time in cold water as $50 \mathrm{~min}$, we may calculate the loss of heat from the blubber, providing heat transfer via blood and conduction from deeper tissues prevents the temperature from dropping significantly, as

$$
Q=\frac{0.0005 \times 74 \times 10^{4}(29-4) 50 \times 60}{8.5 \times 1000}=0.3 \times 10^{4} \mathrm{kcal}
$$

This assumes that the peripheral blood system is contracted and not carrying heat to the surface.

The true loss might be expected to be lower than this value since the slight change in gradient between the blubber and sea water during the loss of heat would lower the temperature of the blubber very slightly.

The drop in temperature would be very slight since, assuming no influx of heat from the deeper tissues, a loss of $0.3 \times 10^{4} \mathrm{kcal}$ from the blubber could cause a drop in blubber temperature of less than

$$
\frac{C}{V \times S}=\frac{0.3 \times 10^{4}}{1.3 \times 10^{4} \times 0.5}=0.5^{\circ} \mathrm{C}
$$


where $V=$ volume of blubber in litres $\left(1.3 \times 10^{4} 1\right.$, Clarke, 1978a), $C=$ kilocalories, $S=$ specific heat of oil (this is close to 0.5 for a variety of oils, Lange, 1967).

Thus, during a dive of even 50 min duration, the blubber would cool rather little and the whale's density would decrease less than $2 \mathrm{~kg}$ due to cooling. This low loss of heat also means that as the blubber oil is compressed during the descent its temperature will rise and its density will drop unless heat is actively (with the aid of the blood circulation) lost. During the descent to $1000 \mathrm{~m}$, the density of the blubber oil of the 30-tonne whale will be decreased by $4 \mathrm{~kg}$. The resulting increase in lift is included in the buoyancy estimate where it seems unlikely that active heat loss through the blubber of the body takes place.

Solid part of tissues. Approximately $50-60 \%$ of adult mammals is water (Altmann \& Dittmar, 1968) and, of the remainder, in a 30-tonne sperm whale, about $24 \%$ of the body weight is oil (Clarke, $1978 a$ ) so that about $16-26 \%$ is solid. Although a proportion of the solid will probably be combined with water in a way which will influence its compressibility, nearly all the solid fraction will be only very slightly compressible and, as the sea water is compressed with increase in pressure, the diving whale will be given extra lift. For example, in a 30-tonne whale diving to $1000 \mathrm{~m}$ where pressure alone will make the density of the sea water 0.0046 higher than at the surface, incompressibility of the solids will cause a lift of

$$
30 \times 10^{3} \times 0.16 \times 0.0046=22 \mathrm{~kg} \text {, }
$$

assuming $16 \%$ of the whale is solid, or $36 \mathrm{~kg}$ assuming $26 \%$ is solid. As we do not know the exact value for the solid fraction or its variability, we must accept that its effect on buoyancy probably lies between 22 and $36 \mathrm{~kg}$.

To summarize, during a dive the effect of compression of tissues on the buoyancy of the whale will be linear with respect to depth and pressure. In a 30-tonne whale diving to $1000 \mathrm{~m}$ it will probably be near

$$
29+4-13=20 \mathrm{~kg} \mathrm{lift},
$$

but lift could be as much as $27 \mathrm{~kg}$ or as little as $13 \mathrm{~kg}$.

\section{Effect of pressure on lung gas}

The final factor influencing buoyancy during a dive is the effect of pressure on gas retained in the lungs. As the whale sinks, the gas in the lungs is compressed according to Boyle's Law, $P V=K$, so that at $1000 \mathrm{~m}$ or 101 bars, the air volume is 0.0099 of its volume at the surface. Clearly, this will cause a large change in buoyancy, particularly if the lungs are full when the whale dives. Sperm whales probably sometimes exhale before diving (personal communication from Dr R. Gambell's observations at Durban), but they are not always seen to do so (this was specially looked for by Mr N. Merrett in an encounter with sperm whales on a calm day in the Indian Ocean, and by my own observations including examination of film), and it is probable that they vary their behaviour in this respect. However, we cannot be certain since exhalation a few metres below the surface might not be visible to an observer on the surface. The expanded lung volume of a 30-tonne whale has not been accurately determined but it can be estimated at between 600 and 8001 , and is probably close to 7001 (Clarke, 1978a). The tidal air in 
deep diving Cetacea is $80-85 \%$ of the lung volume (Scholander, 1940; Slijper, 1962). The air left in the lung after exhalation is therefore 105-140 1. Loss of buoyancy if the whale dives with lungs full or after exhalation with 1201 is given in Table 3 and Fig. 1; almost $90 \%$ of the change occurs in the top $80 \mathrm{~m}$.

It is worth while considering the effect on buoyancy if lungs are at the limits of two estimates for lung volume (i.e. 600 and 800 l). Shallower than about $50 \mathrm{~m}$ the lungs make

Table 3. Decrease in buoyancy of a 30-tonne whale with its lungs full and after exhalation if it were to dive to $3000 \mathrm{~m}$ and only pressure on the gas has any effect

$\begin{array}{rcccc}\begin{array}{c}\text { Depth } \\ (\mathrm{m})\end{array} & \begin{array}{c}\text { Vol of lungs } \\ (\mathrm{l})\end{array} & \begin{array}{c}\text { Decrease in lift } \\ (\mathrm{kg})\end{array} & \begin{array}{c}\text { Vol. residual air } \\ (\mathrm{l})\end{array} & \begin{array}{r}\text { Decrease } \\ (\mathrm{kg})\end{array} \\ 0 & 700 & - & 120 & - \\ 80 & 78 & 622 & 13 & 107 \\ 120 & 54 & 646 & 10 & 110 \\ 200 & 33 & 667 & 6 & 114 \\ 500 & 14 & 686 & 2 & 118 \\ 1000 & 7 & 693 & 1 & 119 \\ 1500 & 5 & 695 & & \\ 2000 & 3 & 697 & & \\ 3000 & 2 & 698 & & \end{array}$

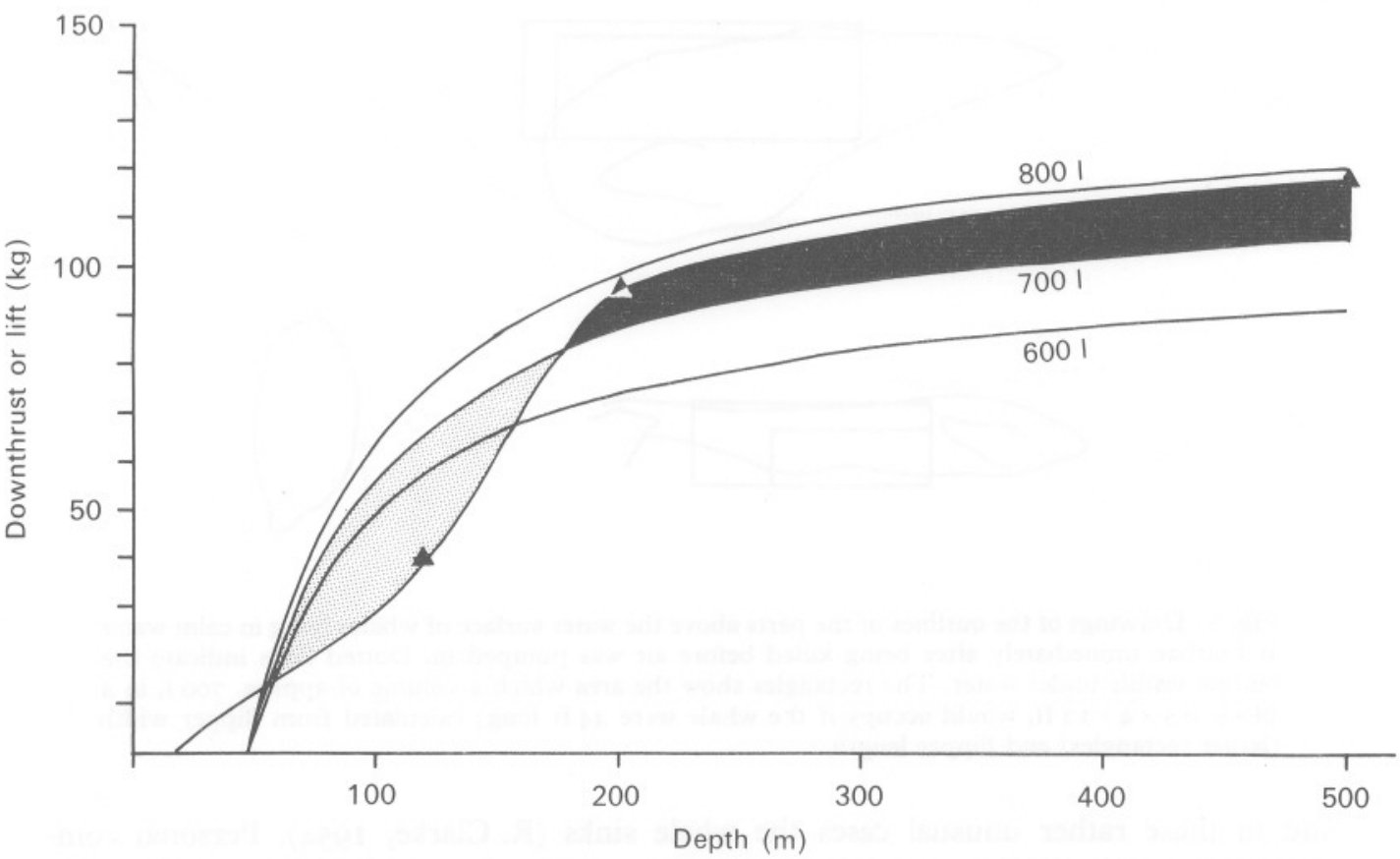

Fig. 1. The downthrust experienced by a diving 30-tonne whale caused by the collapse of its lungs due to pressure assuming a lung volume of 600,700 and 8001 respectively and no upthrust from change in sea-water density. The lift experienced by the whale, due to other factors and ignoring the effect of lung collapse, was calculated from oceanographic data at three depths (triangles) and a line interpolating and extrapolating to the sea surface is drawn in with the aid of temperature profiles on the Equator and density profiles from within the tropics. The black and shaded areas show the difference between this lift and the downthrust caused by lung collapse if the lung is 7001 in volume. 
the whale positively buoyant, but as it dives deeper the collapse of the lungs gives progressively more downthrust. Fig. 1 shows the downthrust produced on a 30-tonne whale by lungs of 800,700 and 6001 .

\section{Buoyancy of the whale when on the surface}

To understand the buoyancy relationships of the whale, it is necessary to know its buoyancy at some position in its range. No measurement of this has been made. However, as has long been known by whalers, this species is generally buoyant at the surface throughout its range (Beale, 1838). It is also evident that it is not buoyant when its lungs are entirely empty, since air is occasionally lost from the lungs at shooting or via a wound,
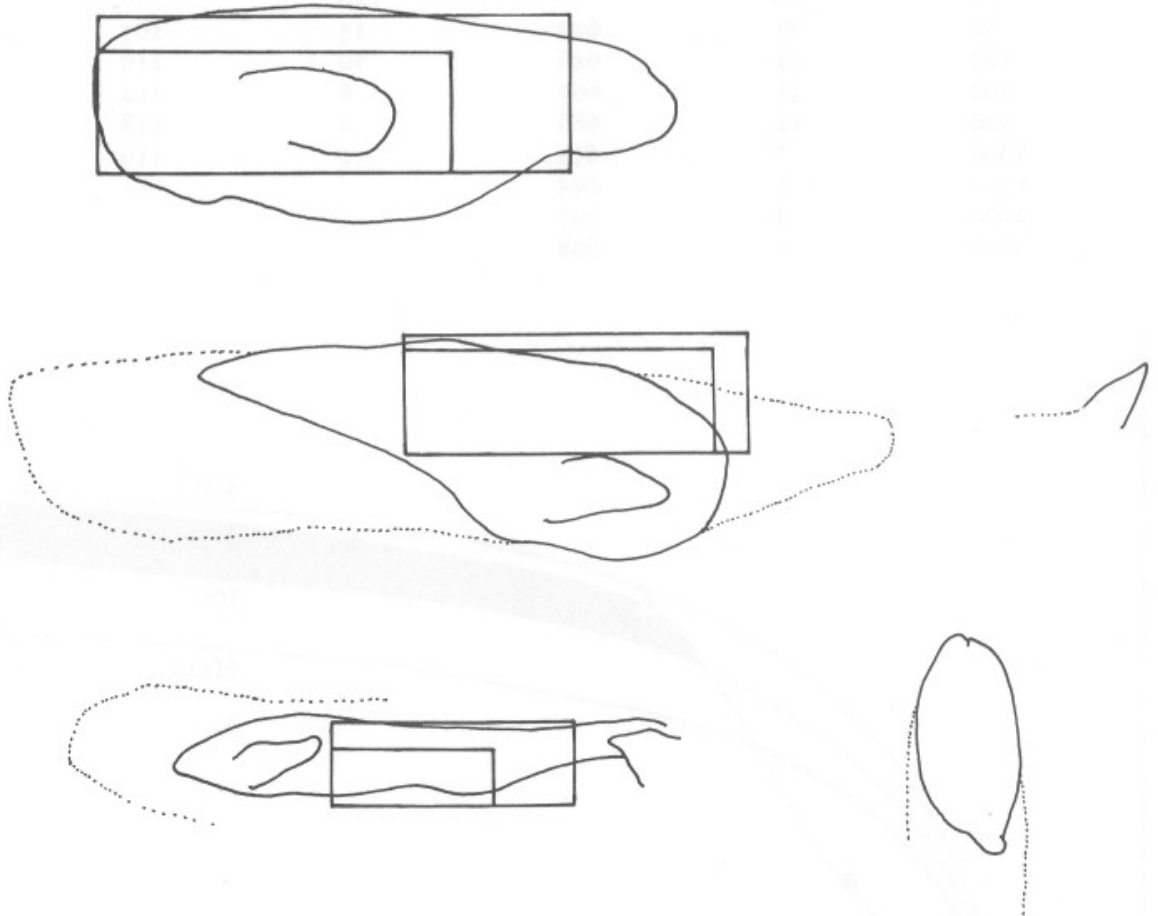

Fig. 2. Drawings of the outlines of the parts above the water surface of whales lying in calm water at Durban immediately after being killed before air was pumped in. Dotted lines indicate the outline visible under water. The rectangles show the area which a volume of approx. 7001 , in a block $0.5 \times 4 \times 12 \mathrm{ft}$, would occupy if the whale were $44 \mathrm{ft}$ long; calculated from flipper width (larger rectangles) and flipper length.

and in these rather unusual cases the whale sinks (R. Clarke, 1954). Personal communication with whalers suggests that this was very unusual off Durban, although a gunner remembered it happening with the whale falling very slowly and being easily recovered on the line. In the Antarctic, Norwegian gunners on a British Factory ship (Fl.F. 'Southern Harvester', 1955-6 season) said they never needed to introduce air into the dead sperm whales to ensure they did not sink when 'buoyed off'. However, apparently Russian whalers use air to give them extra buoyancy and Berzin (1972, 
Table 4. The components of buoyancy of a 30-tonne whale with lungs of $700 l$ at various depths on the Equator and at $55^{\circ} \mathrm{S}$ diving with full lungs or after expiration

$\mathrm{L}=$ lift, $\mathrm{D}=$ downthrust, $\mathrm{N}=$ neutral.

Depth

(1) Dive with full lungs

A Equator: neutral lungs empty (120 1)

B

$55^{\circ} \mathrm{S}: 105 \mathrm{~L}$ with lungs empty

(2) Dive with empty lungs

A

$$
\text { Equator: neutral lungs empty }
$$
(120 L)

B

$55^{\circ} \mathrm{S}: 105 \mathrm{~L}$ with lungs empty

\begin{tabular}{|c|c|c|c|c|c|c|c|}
\hline \multicolumn{7}{|c|}{ Depth } & \multirow{2}{*}{$\begin{array}{c}\text { Explanation of } \\
\text { columns }\end{array}$} \\
\hline$\circ$ & $120 / 100$ & 200 & 500 & 1000 & 1500 & 2000 & \\
\hline \multirow[t]{2}{*}{$\mathrm{N}-580 \mathrm{~L}$} & $\begin{array}{l}66 \mathrm{D} \\
38 \mathrm{~L} \\
2 \mathrm{~L}\end{array}$ & $\begin{aligned} 87 \mathrm{D} \\
92 \mathrm{~L} \\
4 \mathrm{~L}\end{aligned}$ & $\begin{array}{c}106 \mathrm{D} \\
109 \mathrm{~L} \\
10 \mathrm{~L}\end{array}$ & $\begin{aligned} 113 \mathrm{D} \\
118 \mathrm{~L} \\
20 \mathrm{~L}\end{aligned}$ & $\begin{array}{l}115 \mathrm{D} \\
127 \mathrm{~L} \\
30 \mathrm{~L}\end{array}$ & $\begin{array}{l}116 \mathrm{D} \\
129 \mathrm{~L} \\
40 \mathrm{~L}\end{array}$ & $\begin{array}{l}\text { Lungs } \\
\text { SW density (depth) } \\
\text { Pressure on tissues }\end{array}$ \\
\hline & $26 \mathrm{D}$ & $9 \mathrm{~L}$ & $13 \mathrm{~L}$ & $25 \mathrm{~L}$ & $42 \mathrm{~L}$ & $53 \mathrm{~L}$ & Total \\
\hline \multirow[t]{2}{*}{$105-685 \mathrm{~L}$} & $\begin{array}{rl}56 & \mathrm{D} \\
5 \mathrm{~L} \\
2 \mathrm{~L} \\
105 \mathrm{~L}\end{array}$ & $\begin{array}{rl}87 & \mathrm{D} \\
14 \mathrm{~L} \\
4 \mathrm{~L} \\
105 \mathrm{~L}\end{array}$ & $\begin{array}{r}106 \mathrm{D} \\
20 \mathrm{~L} \\
10 \mathrm{~L} \\
105 \mathrm{~L}\end{array}$ & $\begin{aligned} 113 \mathrm{D} \\
23 \mathrm{~L} \\
20 \mathrm{~L} \\
105 \mathrm{~L}\end{aligned}$ & $\begin{array}{r}115 \mathrm{D} \\
24 \mathrm{~L} \\
30 \mathrm{~L} \\
105 \mathrm{~L}\end{array}$ & $\begin{array}{r}116 \mathrm{D} \\
24 \mathrm{~L} \\
40 \mathrm{~L} \\
105 \mathrm{~L}\end{array}$ & $\begin{array}{l}\text { Lungs } \\
\text { SW density. (depth) } \\
\text { Pressure on tissues } \\
\text { SW density (latitude) }\end{array}$ \\
\hline & $56 \mathrm{~L}$ & $36 \mathrm{~L}$ & $29 \mathrm{~L}$ & $35 \mathrm{~L}$ & $44 \mathrm{~L}$ & $53 \mathrm{~L}$ & Total \\
\hline \multirow[t]{2}{*}{$\mathrm{N}-580 \mathrm{~L}$} & $\begin{array}{rl}111 & \mathrm{D} \\
38 \mathrm{~L} \\
2 \mathrm{~L}\end{array}$ & $\begin{array}{rl}114 & \mathrm{D} \\
92 & \mathrm{~L} \\
4 & \mathrm{~L}\end{array}$ & $\begin{array}{r}118 \mathrm{D} \\
109 \mathrm{~L} \\
10 \mathrm{~L}\end{array}$ & $\begin{array}{r}119 \mathrm{D} \\
118 \mathrm{~L} \\
20 \mathrm{~L}\end{array}$ & $\begin{array}{r}120 \mathrm{D} \\
127 \mathrm{~L} \\
30 \mathrm{~L}\end{array}$ & $\begin{array}{l}120 \mathrm{D} \\
129 \mathrm{~L} \\
40 \mathrm{~L}\end{array}$ & $\begin{array}{l}\text { Lungs } \\
\text { SW density (depth) } \\
\text { Pressure on tissues }\end{array}$ \\
\hline & $71 \mathrm{D}$ & $18 \mathrm{D}$ & $1 \mathrm{~L}$ & $19 \mathrm{~L}$ & $37 \mathrm{~L}$ & $49 \mathrm{~L}$ & Total \\
\hline \multirow[t]{2}{*}{$105-685 \mathrm{~L}$} & $\begin{aligned} 109 \mathrm{D} \\
5 \mathrm{~L} \\
2 \mathrm{~L} \\
105 \mathrm{~L}\end{aligned}$ & $\begin{aligned} 114 \mathrm{D} \\
14 \mathrm{~L} \\
4 \mathrm{~L} \\
105 \mathrm{~L}\end{aligned}$ & $\begin{aligned} 118 \mathrm{D} \\
20 \mathrm{~L} \\
10 \mathrm{~L} \\
105 \mathrm{~L}\end{aligned}$ & $\begin{aligned} 119 \mathrm{D} \\
23 \mathrm{~L} \\
20 \mathrm{~L} \\
105 \mathrm{~L}\end{aligned}$ & $\begin{array}{r}120 \mathrm{D} \\
24 \mathrm{~L} \\
30 \mathrm{~L} \\
105 \mathrm{~L}\end{array}$ & $\begin{array}{l}120 \mathrm{D} \\
24 \mathrm{~L} \\
40 \mathrm{~L} \\
105 \mathrm{~L}\end{array}$ & $\begin{array}{l}\text { Lungs } \\
\text { SW density (depth) } \\
\text { Pressure on tissues } \\
\text { SW density (latitude) }\end{array}$ \\
\hline & $2 \mathrm{~L}$ & $9 \mathrm{~L}$ & $17 \mathrm{~L}$ & $29 \mathrm{~L}$ & $39 \mathrm{~L}$ & $49 \mathrm{~L}$ & Total \\
\hline
\end{tabular}


p. 314) states 'at present, sperm whales are considered to sink after death, and in fact, some of them do, primarily young animals that have a smaller amount of fat'. In contradiction to this, Berzin (1972, p. 262) also states: 'the body of a whale, particularly when the lungs are filled with air, has a positive buoyancy and is maintained automatically at the surface'. Observations during capture (personal and by whalers, e.g. in Beale, 1838) and outlines of freshly killed whales taken from $8 \mathrm{~mm}$ cine film show that the whales protrude above the water for a few inches. The rectangles in Fig. 2 represent the area covered by 7001 (the lung volume) at a thickness of 6 in if the whales are taken to be $44 \mathrm{ft}$ long. The size of these rectangles is based upon the width and length of the flipper which represent $4.5 \%$ and $10 \%$ of the length of a whale of this size. As the area of the whale exposed probably averages $3-6$ in in depth, it will be seen that the area exposed certainly approaches the lung in volume.

Indeed, it seems likely that less than $15-20 \%$ of the lung volume (the air left in the lung after expiration) would be air filled when the whale is neutrally buoyant. This would mean that the whale would be buoyant throughout its breathing cycle at the surface and would normally float at capture. It could, however, sink if the lungs were damaged and air escaped. The extremely elastic nature of the lung (Slijper, 1962; Berzin, 1972) would contribute to a ready loss of gas if the lungs were penetrated by a harpoon.

\section{Buoyancy of the whale over its range}

Having discussed each factor influencing the whale's buoyancy, these will now be considered together and alternative possibilities considered.

Because observation shows the whale to be buoyant after exhalation in the Tropics, when it moves to the Antarctic it must have even more positive buoyancy. Although we do not know its precise buoyancy at the surface, the variation in buoyancy at depths over $100 \mathrm{~m}$ will be the same whatever the exact buoyancy after exhalation at the surface. Table 4 summarizes the effect on the buoyancy of a 30-tonne whale at the surface and at selected depths if the whale is neutrally buoyant after exhalation on the Equator. The four factors, lung collapse, change in ambient sea-water density during a dive, effects of pressure on tissues and the change in ambient sea-water density during migration, are given for each alternative. The fluctuation in buoyancy at the surface resulting from breathing is also shown.

Fig. 3 shows the overall change in buoyancy of a 30-tonne whale diving to selected depths on the Equator or at $55^{\circ} \mathrm{S}$ with lungs full or after exhalation. As mentioned above, there is some doubt regarding the amount of solid in the whale and, consequently, also regarding the effect of pressure on its tissues and its buoyancy. Limits on the buoyancy, assuming the whale includes $16 \%$ and $26 \%$ solids, is given for one of the four alternatives in Fig. 3. The same range at each respective depth also applies for the other alternatives. The overall range in lift deeper than $200 \mathrm{~m}$ for the upper and lower limits of solid content would be $30 \mathrm{~kg}$ and $57 \mathrm{~kg}$ respectively. For calculation of buoyancy control, the middle values for solid content will be used (Table 4, Fig. 3).

Deeper than $500 \mathrm{~m}$ the whale experiences lift anywhere in its range, whether it dives with lungs full or after exhalation. Shallower than $200 \mathrm{~m}$ on the Equator, the whale experiences a downthrust with a greater maximum if it dives after exhalation than if it 
dives with lungs full (Table 4). The exact values of the maximum or its depth cannot be determined from the available data. However, in Fig. 1 the general area of downthrust (shaded area) is shown for a 30-tonne whale with 7001 lungs by comparing the lift produced by sea-water density and compression of tissues with the downthrust produced by lung collapse. The curve showing lift has been interpolated and extrapolated by reference to sea-water temperature profiles on the Equator and density profiles within the Tropics. The triangles represent the calculated points from Table 4 . This shows that

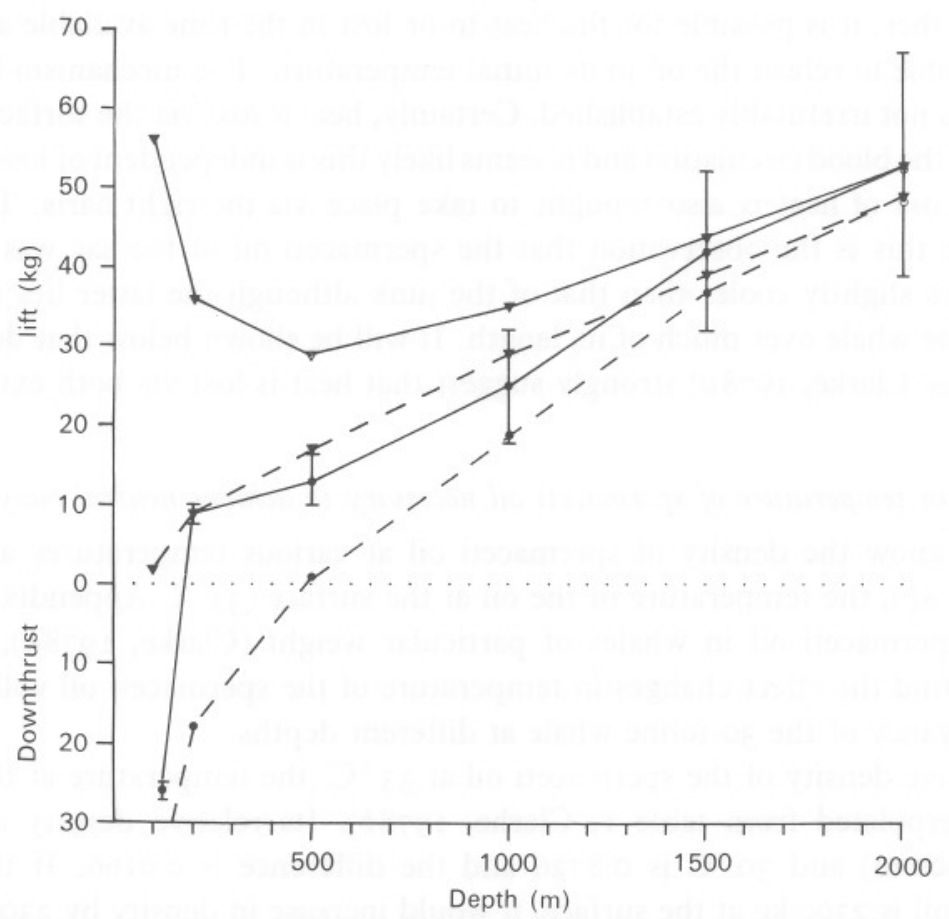

Fig. 3. The lift or downthrust experienced by a 30-tonne sperm whale at different depths at $55^{\circ} \mathrm{S}$ (triangles) and on the Equator (circles) diving with lungs full (solid lines) or after exhalation (broken lines), assuming the whale is neutrally buoyant after exhalation on the Equator at the surface. For explanation of the vertical range lines at each depth see text (p. $\left.3^{8}\right)$.

the whale on the Equator has a maximum downthrust of about $30 \mathrm{~kg}$ near $100 \mathrm{~m}$ in depth. If the lungs were less than 7001 this downthrust would be less; about $20 \mathrm{~kg}$ for 6001 lungs. If the whale had 8001 lungs this downthrust would be abcut $35 \mathrm{~kg}$ and would be a few $\mathrm{kg}$ all the way down to $500 \mathrm{~m}$. Deeper, however, the lift would equal and then exceed the downthrust until at $1000 \mathrm{~m}$ it would exceed it by $9 \mathrm{~kg}$ and at $2000 \mathrm{~m}$ by $36 \mathrm{~kg}$. Thus, even if the lung size were exactly matched to tissue in some way to make the whale neutral from 200 to $500 \mathrm{~m}$, neutrality would still not be obtained at greater depths or, of course, in different regions. 


\section{Control of buoyancy}

As shown in Fig. 3, if the whale needs to achieve neutral buoyancy it must be able to increase its own density by $35-67 \mathrm{~kg}$ over some of its range. The necessary increase can be achieved if the whale can lower the temperature of the spermaceti oil of its head so that it freezes. Below, it will be shown that, in a whale at the sea surface at Durban, the spermaceti oil is only slightly above the temperature at which it starts freezing and it would only need to drop the temperature $3-4{ }^{\circ} \mathrm{C}$ to achieve the necessary increase in density. Further, it is possible for the heat to be lost in the time available and sufficient heat is available to reheat the oil to its initial temperature. The mechanism by which the heat is lost is not irrefutably established. Certainly, heat is lost via the surface of the head by means of the blood circulation and it seems likely this is independent of loss of heat from the body. Loss of heat is also thought to take place via the right naris. The strongest evidence for this is the observation that the spermaceti oil of the sac was found to be nearly always slightly cooler than that of the junk although the latter lies nearer to the outside of the whale over much of its length. It will be shown below that details of head structure (see Clarke, 1978a) strongly suggest that heat is lost via both exits.

\section{The change in temperature of spermaceti oil necessary to achieve neutral buoyancy}

Now we know the density of spermaceti oil at various temperatures and pressures (Clarke, 1978b), the temperature of the oil at the surface $\left(33^{\circ} \mathrm{C}\right.$ Appendix III) and the weight of spermaceti oil in whales of particular weight (Clarke, 1978a), we are in a position to find the effect changes in temperature of the spermaceti oil will have on the overall buoyancy of the 30 -tonne whale at different depths.

The relative density of the spermaceti oil at $33^{\circ} \mathrm{C}$ (the temperature at the surface) is 0.8560 (interpolated from table 1 , Clarke, $1978 b$ ). Its relative density at 107.0 bars (approx. $1000 \mathrm{~m}$ ) and $30{ }^{\circ} \mathrm{C}$ is 0.8726 and the difference is 0.0166 . If the weight of spermaceti oil is $2300 \mathrm{~kg}$ at the surface, it would increase in density by $2300 \times 0.0166=$ $38 \mathrm{~kg}$ with this change in temperature and pressure. However, the change in density due to compression of sea water must be taken into account (Table 1).

The effect on the buoyancy of the whale can be determined from

$$
\begin{aligned}
& \text { weight of the spermaceti oil }(\mathrm{kg}) \\
& \times\left(\frac{\text { density of sea water at surface }}{\text { density of oil at surface }}-\frac{\text { density of sea water at depth }}{\text { density of oil at depth }}\right) .
\end{aligned}
$$

For the present example at the Equator the whale would experience a downthrust of

$$
2300\left(\frac{1 \cdot 02353}{0.8560}-\frac{1 \cdot 03207}{0.87260}\right)=29.8 \mathrm{~kg}
$$

due to the spermaceti oil at a depth of $1000 \mathrm{~m}$, providing the temperature of the oil drops $3{ }^{\circ} \mathrm{C}$ (i.e. to $30^{\circ} \mathrm{C}$ ).

Taking the lifts for every depth in the four alternatives given in Table 4 it is possible 
to calculate the relative density of the oil necessary to produce a downthrust equivalent to the lift at the particular depth in a 30-tonne whale from

$$
\frac{\text { sea water relative density at depth (including pressure effect) }}{\left(\frac{\text { sea water relative density at surface }}{\text { oil relative density at surface }}\right)-\left(\frac{\text { lift }}{2300}\right)} \text {. }
$$

The oil density required to match the lift at each depth is given for each alternative in Fig. 4. By plotting these densities for every depth on a graph showing density, pressure and temperature relationships of the oil (Clarke, 1978b), the temperatures to which the oil must be lowered to obtain the required densities is indicated.

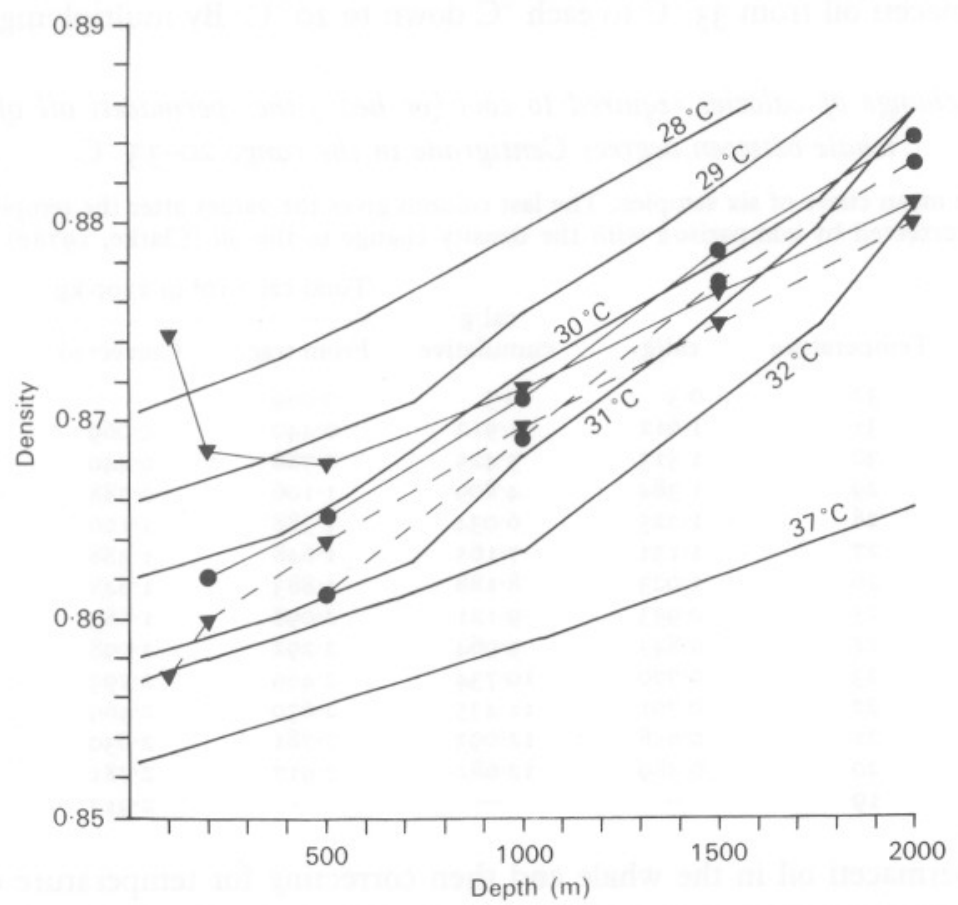

Fig. 4. The relative density of the spermaceti oil which is necessary to match the lift of a $30-$ tonne whale at various depths (Fig. 3) at $55^{\circ} \mathrm{S}$ (triangles) and on the Equator (circles) diving with lungs full (solid lines) or after exhalation (broken lines) assuming the whale is neutrally buoyant after exhalation on the Equator. Plots of temperature against density of the spermaceti oil are also shown.

From Fig. 4, it is at once clear that, firstly, in all alternatives over the operational depth range $\left(>200 \mathrm{~m}\right.$ ), temperatures need only be lowered to $29-32{ }^{\circ} \mathrm{C}$ to obtain the required densities. Secondly, to match the lift at $100 \mathrm{~m}$ at $55^{\circ} \mathrm{S}$ if the whale dived with full lungs the oil temperature would have to drop to $27.0^{\circ} \mathrm{C}$. As shown below (p. 50) such a drop in temperature during the dive would be unlikely since a very large quantity of heat $\left(1.44 \times 10^{4} \mathrm{kcal}\right)$ would be required to warm it up again. Thirdly, if the whale dived after exhalation at $55^{\circ} \mathrm{S}$ and with full lungs on the Equator, the oil would not need to drop to less than about $30^{\circ} \mathrm{C}$ to match the lift at any depth. This variation in behaviour would clearly be very advantageous and may account for differences between the 
descriptions of different observers, some of which think sperm whales breathe in before sounding, and others which think they breathe out (p. 34). Fourthly, the slope of the lines showing the densities which must be matched, bears a striking similarity to the general slope of the temperature lines of the spermaceti oil. This would seem good supporting evidence for the hypothesis advanced here. The extreme limit of lift calculated for $2000 \mathrm{~m}(67 \mathrm{~kg}$, Fig. 3) could be countered by a drop in temperature of the oil to near $29^{\circ} \mathrm{C}$.

\section{The loss of heat from the spermaceti oil necessary to achieve neutral buoyancy}

Clarke $(1978 b)$ published a table showing the exchange of calories per gram required to cool spermaceti oil from $33{ }^{\circ} \mathrm{C}$ to each ${ }^{\circ} \mathrm{C}$ down to $20^{\circ} \mathrm{C}$. By multiplying this by the

Table 5. Exchange of calories required to cool (or heat) the spermaceti oil of a 30-tonne whale between degrees Centigrade in the range $20-33^{\circ} \mathrm{C}$

Derived from a mean curve of six samples. The last column gives the values after the temperature scale is corrected by comparison with the density change of the oil (Clarke, 1978b).

\begin{tabular}{|c|c|c|c|c|}
\hline \multirow[b]{2}{*}{ Temperature } & \multirow[b]{2}{*}{$\mathrm{cal} / \mathrm{g}$} & \multirow{2}{*}{$\begin{array}{l}\mathrm{cal} / \mathrm{g} \\
\text { cumulative }\end{array}$} & \multicolumn{2}{|c|}{ Total cal $\times 10^{4}$ in $2300 \mathrm{~kg}$} \\
\hline & & & From trace & Corrected \\
\hline 32 & 0.3 & 0.3 & 0.069 & \\
\hline 31 & $1 \cdot 612$ & 1.912 & 0.440 & 0.069 \\
\hline 30 & $1 \cdot 513$ & 3.425 & 0.788 & 0.440 \\
\hline 29 & $1 \cdot 384$ & 4.809 & $1 \cdot 106$ & 0.788 \\
\hline 28 & 1.225 & 6.034 & $1 \cdot 388$ & $1 \cdot 106$ \\
\hline 27 & 1.131 & $7 \cdot 165$ & $1 \cdot 648$ & 1.388 \\
\hline 26 & 1.023 & 8.188 & 1.883 & 1.648 \\
\hline 25 & 0.933 & 9.121 & 2.098 & 1.883 \\
\hline 24 & 0.843 & 9.964 & 2.292 & 2.098 \\
\hline 23 & 0.770 & $10 \cdot 734$ & 2.469 & $2 \cdot 292$ \\
\hline 22 & 0.701 & 11.435 & 2.630 & $2 \cdot 469$ \\
\hline 21 & 0.658 & 12.093 & $2 \cdot 781$ & 2.630 \\
\hline 20 & 0.589 & $12 \cdot 682$ & $2 \cdot 917$ & $2 \cdot 781$ \\
\hline 19 & - & - & - & $2 \cdot 917$ \\
\hline
\end{tabular}

weight of spermaceti oil in the whale and then correcting for temperature error in the experiment, the heat which a 30 -tonne whale must lose in order to drop its spermaceti oil in temperature can be found (Column 5, Table 5, Fig. 5). To drop the temperature from 33 to $30^{\circ} \mathrm{C}$ the oil must lose $0.44 \times 10^{4} \mathrm{kcal}$ of 'latent' heat. In addition, it must also lose heat which is produced when the oil is compressed. Clarke (1978b) showed that when spermaceti oil was compressed at a starting temperature of about $31^{\circ} \mathrm{C}$ it rose in temperature by $0.8^{\circ} \mathrm{C}$ at $1000 \mathrm{~m}$ and this rise would be similar at a starting temperature of $33^{\circ} \mathrm{C}$. The additional heat which would have to be removed can also be determined from Fig. 5 and the whale diving to $1000 \mathrm{~m}$ would have to lose an extra $0.29 \times 10^{4} \mathrm{kcal}$ to achieve the drop in temperature to $30^{\circ} \mathrm{C}$.

Fig. 6 shows the heat which would have to be lost to achieve neutral buoyancy in a whale of 30 tonnes diving with full lungs or after exhalation on the Equator and at $55^{\circ} \mathrm{S}$. Deeper than $2000 \mathrm{~m}$, very little heat needs to be lost for neutral buoyancy or even lift to be achieved.

It is now necessary to calculate whether or not it is possible for the whale to lose this 
amount of heat in the time available. But first, the two alternative mechanisms for losing heat - blood flow through the skin of the head or passage of heat into water drawn into the right naris - must be described in detail.

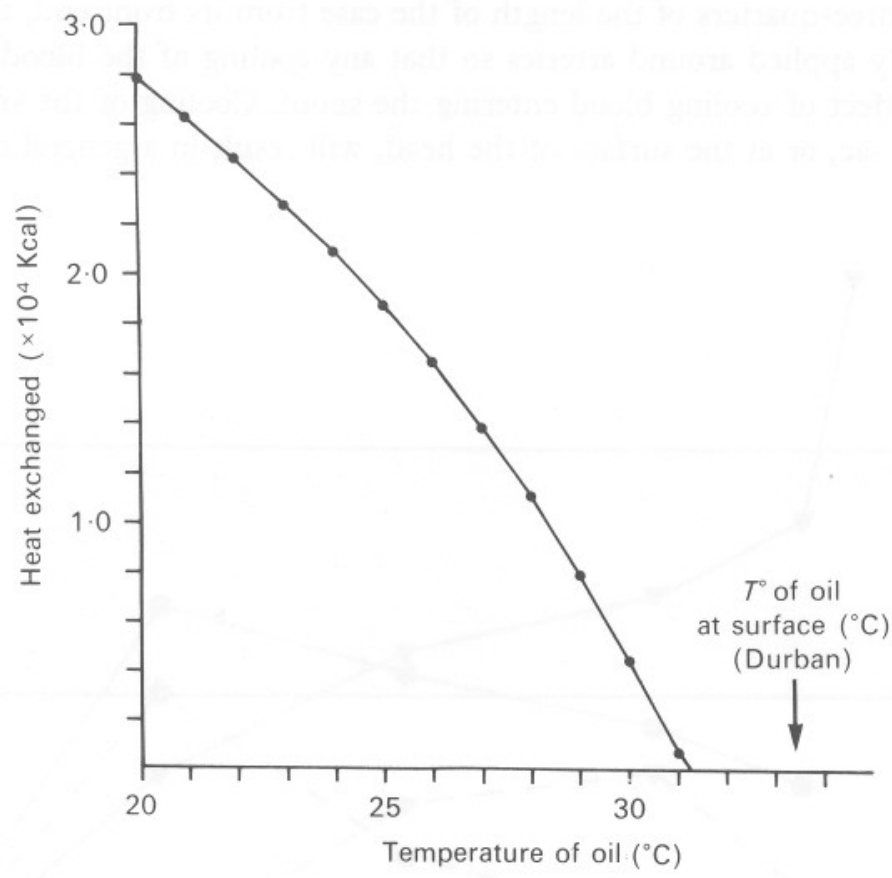

Fig. 5. A cumulative curve showing the heat which must be lost in order to decrease the temperature of the spermaceti oil in the head of a 30-tonne whale from $33{ }^{\circ} \mathrm{C}$ to successive temperatures down to $20^{\circ} \mathrm{C}$. Derived from Clarke $(1978 b)$.

\section{The mechanism of losing heat}

Heat loss via the surface of the head. The quantity of heat to be lost from the spermaceti oil and the time available precludes its loss by passive conduction from the head surface. This is shown conclusively by the negligible drop in temperature of the spermaceti oil even after $20 \mathrm{~h}$ post-mortem time (Appendix III) and an experiment using water in the right naris (Appendix IV). Loss of heat from the surface of the head can be greatly increased by vasodilation of the skin capillaries (p. 50) and in particular the junk is probably mainly cooled in this way. At the front and sides of the head the junk fat is within $11 \mathrm{~cm}$ of the surface in a $47 \mathrm{ft}(14.3 \mathrm{~m})$ whale. The junk is wedge-shaped from the side and its dorsal width roughly equals its maximum depth. It is narrower underneath anteriorly. The lower part of the maxillonasalis muscle lies between the junk and the head surface for half the junk's length. In a $47 \mathrm{ft}(14.3 \mathrm{~m})$ whale this reduces the area over which loss of heat by direct conduction from the junk can take place to about $4.5 \mathrm{~m}^{2}$. However, the area of the head surface in front of the eye is about $24.0 \mathrm{~m}^{2}$ in a 30-tonne whale (Clarke, 1978a), and general cooling of the head tissues could take place by cooling of the blood over all this area after it has passed through the junk, sac and other head tissues. 
The dermal papillae of the head (Clarke, 1978a) provide an effective means of carrying blood and heat to the surface. Blood leaving the anterior end of the spermaceti sac, the blubber and the junk tissues, drains into veins which run closely alongside the branches of the maxillary artery. Before and after passing through the skull, at a position two-thirds to three-quarters of the length of the case from its front end, the branching veins are closely applied around arteries so that any cooling of the blood in the snout will have the effect of cooling blood entering the snout. Cooling of the snout either in the spermaceti sac, or at the surface of the head, will result in a general cooling of the

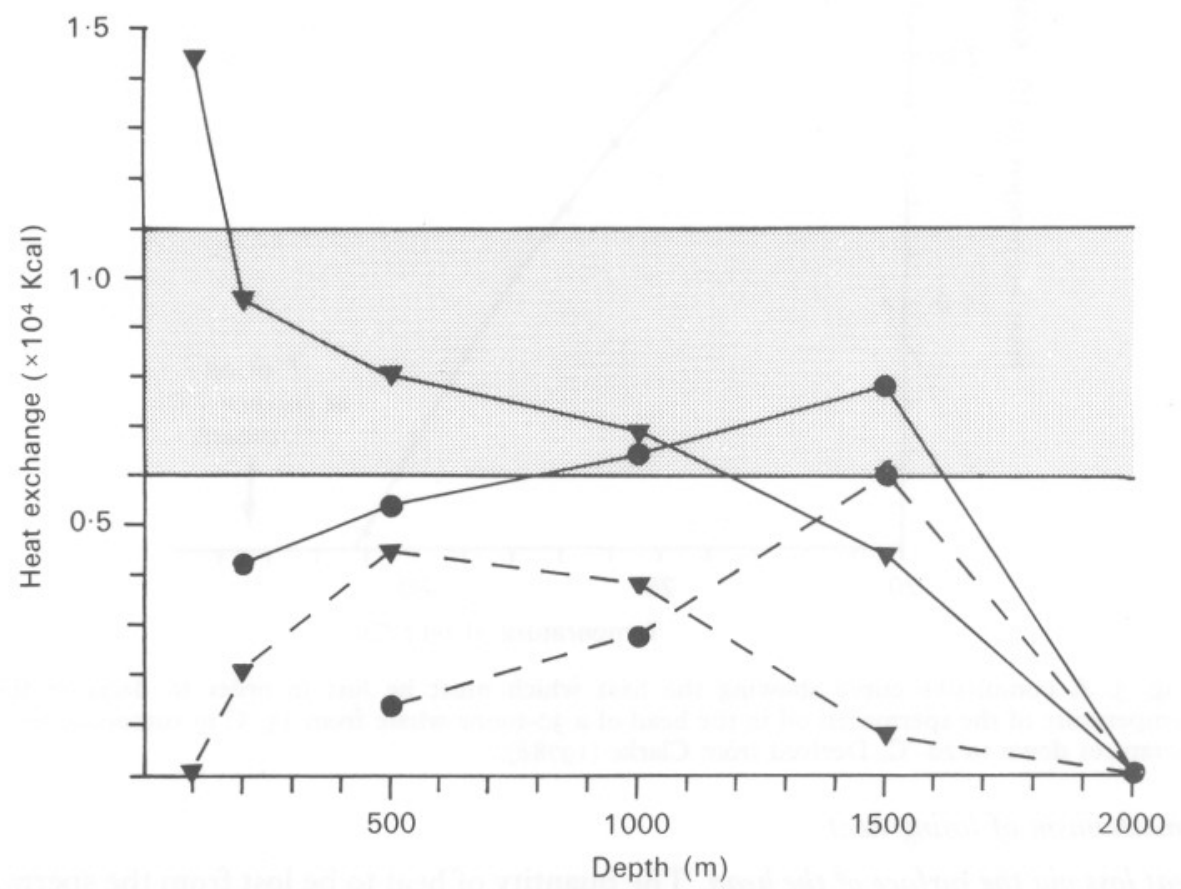

Fig. 6. The calories required to reheat to $33^{\circ} \mathrm{C}$ the spermaceti oil of a 30-tonne sperm whale, diving to various depths and obtaining neutral buoyancy by cooling the oil, at $55^{\circ} \mathrm{S}$ (triangles) and on the Equator (circles) diving with lungs full (solid lines) or after exhalation (broken lines). The whale is assumed to be neutrally buoyant after exhalation on the Equator, at the surface. Estimates of the maximum heat available for reheating the spermaceti oil to $33^{\circ} \mathrm{C}$ during the hour of the diving cycle mainly lie within the shaded area.

whole snout, with a gradient between the cooling surfaces and the posterior end of the snout which receives the blood first. Such a gradient was seen between the anterior and posterior ends of the junk and the sac (Appendix III). The relationship of veins and arteries near the skull is quite adequate for a steep heat gradient to be present between the snout and the rest of the head and body. The front of the junk of many whales examined contained a great deal of blood, causing the first few blocks of spermaceti tissue to be dark red in colour (Clarke, 1978 $a$, pl. II). In these whales, the skin over the tip and sides of the snout had papillae distended with blood. This could easily be seen by rubbing the black epidermis so that the pigmented tissue came away and left the bright red papillae. Clearly, these whales were still actively losing heat from the head 
when killed, although in no instance was any part of the head at a higher temperature than $35^{\circ} \mathrm{C}$ (i.e. $2-3{ }^{\circ} \mathrm{C}$ below the 'normal' body temperature). These whales had possibly been chased for some way and were cooling their heads in preparation for another dive. Whales without such evidence of active cooling had possibly surfaced after a deep dive and had lost the heat produced by activity at depth prior to surfacing. We have no evidence that the peripheral capillaries of the head can be controlled separately from those of the body and, if they cannot, sufficient cooling of the head might lead to too much loss of heat from the body (p. 59). However, it is quite possible that the head can 'blush' independently of the body, and the blood system of the head is certainly arranged to facilitate a general cooling from the anterior towards the posterior end of the snout.

Heat loss via the right naris. While heat from the head is actively lost from its skin, the arrangement and structure of the right naris certainly suggests that this also may be involved in cooling the spermaceti of the head.

The separation of nasal passages, so that the left naris passes outside the case containing the spermaceti oil while the right naris passes directly below the spermaceti sac oil, suggests separate and distinct functions. This is further indicated by the very different wall structure. The tough fibrous lining of the narrow left passage has powerful muscles attached to its concave side which, by contraction, expand the lumen. The right naris has a soft, delicate, non-fibrous, non-muscular lining which is closely covered by the fatty tissue of the spermaceti organ, and has small muscles inserted into its ventral side (Clarke, 1978a).

The shape and size of the right naris, particularly in the adult (Clarke, 1978a), strongly suggests that it is designed to present a large surface area of the inside of the snout to air or water drawn into it. This assumption can account for the enormous dimensions of the main passage and the presence of a large vertical chamber across the posterior end of the spermaceti organ. The anterior vestibular sac lies outside the case and is possibly only large in order to accommodate the broad mouth-like opening of the longitudinal part of the right nasal passage, the museau de singe. In the adult it is surrounded by fibrous tissue, that on the outside forming blubber and that on the inside forming the anterior end of the case. The longitudinal part of the right naris and the nasofrontal sac are broad and flat. The dorsal half of the surface of the former and the anterior half of the surface of the latter are almost directly in contact with the tissue holding the spermaceti oil. The connective tissue ventral to the longitudinal passage has muscles in it and overlies fibrous tissue separating it from the junk. The posterior wall of the nasofrontal sac lies against the crest of the skull.

If the function of the right naris is to cool the spermaceti oil, water would be necessary since the thermal capacity of air is too small, $<0.1 \%$ of sea water, to act as a coolant in the brief time spent at the sea surface. While loss could be speeded up by evaporation of water from the surface of the right naris, the whale could only lose - no. of breaths $\times$ vol. of air in naris $\times \mathrm{g}$ of water at saturation in $1 \mathrm{~m}^{3}$ at $35^{\circ} \mathrm{C} \times$ latent heat of evaporation at $35^{\circ} \mathrm{C}$,

$$
60 \times 0.37 \times 60 \times 580=0.08 \times 10^{4} \mathrm{kcal} \text { per dive. }
$$

This loss would be insufficient for the regulation of buoyancy. Water çould be drawn into the right naris, either via the right opening into the vestibular sac and the museau 
de singe or via the left naris, the common nasopalatine canal and the right nasopalatine opening.

If the first possibility is the normal method, water would be drawn into the submerged blow-hole by contraction of the large maxillonasalis muscles, which are attached to the crest of the skull posteriorly, and are inserted in the anterior half of the hard fibrous case forming the spermaceti sac wall (Clarke, 1978a). Contraction of this muscle has previously been thought to only open the blow-hole or the museau de singe (Pouchet \&

A

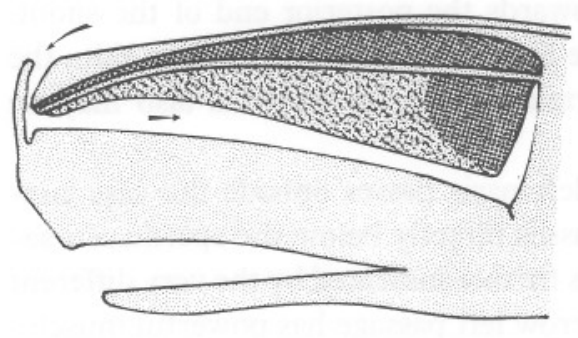

C

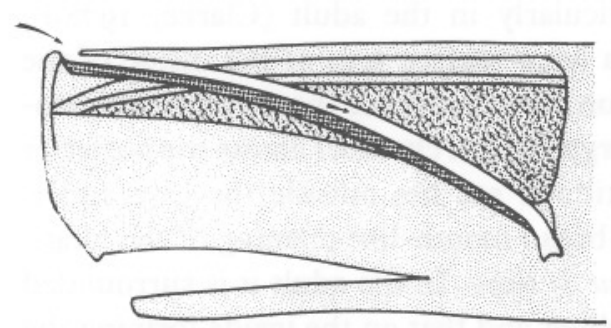

B

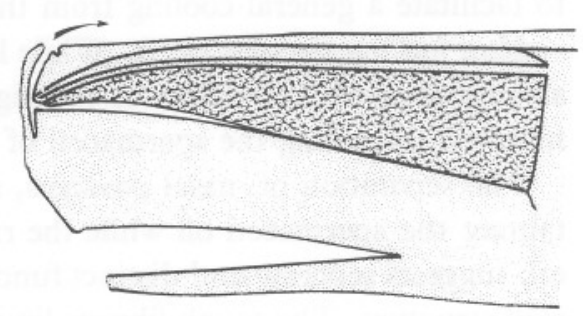

D

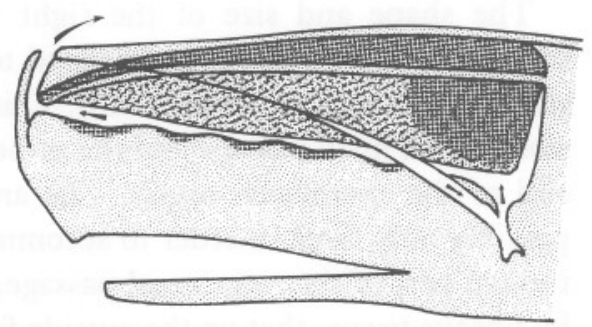

Fig. 7. Two possible ways in which the sperm whale could pass sea water in and out of the right naris. Contracting muscles are shown by heavy dots and water movements by arrows. (A) Contraction of the muscles outside and inside the case draws water into the right naris via the blowhole and (B) their relaxation pushes it out by the elasticity of the case. (C) Water is drawn into the left naris which (D) then relaxes progressively from the anterior end and the contained water is drawn into the right naris and carried forwards by contraction of three sets of muscles.

Beauregard, 1889) or to squeeze the spermaceti sac (Schenkkan \& Purves, 1973). However, in the adult whale, the insertion of the muscles extend over most of the anterior half of the case and their contraction would not only open the museau de singe but would pull the case wall upwards and backwards. This action seems pointless in the foetus, where the case is circular in cross-section, because such contraction could only lead to a squeezing of the spermaceti sac and a closure of all the contained naris while opening the museau de singe. In the grown whale, however, the case is not fully distended with spermaceti oil tissue, and contraction of the maxillonasalis could raise the case and draw water into the anterior half of the naris. Peristaltic-like contractions of the muscles in the floor of the naris could carry boluses of water posteriorly along the naris and water 
could be pulled into the nasofrontal sinus by contraction of the muscles running from near its anterior wall forward into the spermaceti tissue (Fig. 7A). Water would be squeezed from the naris by relaxation of the maxillonasalis muscle and the nasofrontal sac muscles, and possibly by a reversal of the contractions of the muscle ventral to the naris (Fig. 7B). This method would involve water entering the blow-hole from the rear, since the opening of the right vestibule is directed backwards in the grown whale and this would tend to act against the forward movement of the whale if it were swimming. Expelled water would be directed backwards. Perhaps the second method is as likely. By this, water from ahead of the snout is drawn into the left naris by contraction of the powerful left maxillonasalis and maxillolabialis muscles (Fig. 7C). If the blow-hole then closed and the muscles relaxed, elasticity of the fibrous surrounding tissue could push the water via the stiff-walled nasopalatine cavity and right nasopalatine opening into the back of the right naris, near its junction with the nasofrontal sac. This transfer of water would be aided by contraction of the strong muscles inserted in the wall of the nasofrontal sac, and by contraction serially or together of the muscles in the floor of the naris (Fig. 7D). The water within the right naris could be supplemented by several pumps of the left naris.

The narrow opening with a tight sphincter and a non-return valve (see Appendix V), where the right naris opens into the nasopalatine cavity, and the very tight manner in which the lips of the museau de singe are pressed together when the muscles are relaxed are explained if both ends of the right naris need to be tightly shut when water is within it. The museau de singe would hold water within the naris while the right nasopalatine opening would need to open to admit water from the left naris, but would need to close tightly during suction of water into the left naris to avoid water being sucked back from the right naris. The accumulated water would be expelled from the right naris by relaxation of the nasofrontal sac muscles and contraction of the right maxillonasalis, resulting in the opening of the museau de singe and the squeezing of the spermaceti sac (Fig. 7D). Water would leave the blow-hole towards the rear and would not interfere with swimming. The form of the museau de singe and the right nasopalatine opening suggest that a large volume of water is taken into the right naris, and the muscles below the naris and in the spermaceti oil tissue probably act to move it about within the naris. The left naris of a $31 \mathrm{ft}(9.5 \mathrm{~m})$ whale was one-third the volume of the right naris (Clarke, 1978a). For a $46 \mathrm{ft}(14.2 \mathrm{~m})$ whale, the left was 0.22 of the volume of the right naris. Thus, with three to five pumps, the left naris could distend the right naris (neglecting the nasofrontal sac) to a cylindrical form. It may not be necessary for it to do this, and possibly the water from each pump of the left naris is expelled before a further pump; this would be the best method for heat exchange.

In the living whale, heat is moved within the sac and snout generally within blood vessels, and it is by this transfer of heat to the surface of the right naris and to the surface of the head that the insulation properties of the oil can be by-passed, and a general cooling of the sac or head is made possible. The blood circulation of the head is arranged to bring this about.

When cold sea water is admitted into the right naris, direct cooling of the spermaceti oil near the naris must take place. The capillary network would bring more heat from 
the tissues further from the naris wall, so that conduction through the wall and radiation from the wall would continually be maintained at its maximum. Blood that had been cooled would move away from the naris wall and would then cool oil further from the wall. Thus, the effect of this general capillary network in which blood passes forwards from the posterior end will be to facilitate cooling generally throughout the spermaceti organ.

Another result of water entering the naris is that the blood entering the sac near the base of the nasofrontal sinus will be directly cooled. The distance between the sinus and the blood vessel is less than $1 \mathrm{~cm}$ in the $120 \mathrm{~cm}$ foetus, and no fat tissue intervenes. While the distance is not known in the adult, it is not likely to be great, and cold water would certainly cool the tissues and contained blood in this region.

As mentioned above, during cooling, the rete-like mass of blood vessels which lie above the maxilla on each side functions as a means of cooling blood entering the snout in the main arteries by bringing it into contact with blood which is returning from the skin of the head. In the foetus, the rete dorsal to the left maxilla lies directly against and around branches of the left naris near its passage through the skull. Some of these branches lie over the maxilla and premaxilla. Although such branches are possibly present in the adult, they are very much less developed than similar structures in porpoises (Lawrence \& Schevill, 1956). Their close proximity to the rete of the left side would certainly lead to rapid cooling of the blood if the water circulates from the left to the right naris as suggested as one alternative.

To summarize, heat is lost via the surface of the head from the whole snout by active transport by blood circulation. Heat is probably also lost into water entering the right naris. It will be shown below that, for the buoyancy mechanism to operate, the right naris need not necessarily be employed for cooling although the evidence suggests that it is for at least some of the time.

\section{The time required for heat exchange}

The loss of heat by conduction from the body surface and the right naris can be greatly augmented by passing blood at a temperature which is high relative to the ambient water. In the skin, the blood at the tip of the papillae passes within $0.3 \mathrm{~mm}$ of the water and in the naris to within $0.6 \mathrm{~mm}$. By reducing the distance between the blood and the water, and by keeping the thermal gradient very steep by constant replacement of blood, very efficient heat transfer is possible. The heat transferred $(Q)$ may be calculated from formula 1 (p. 33).

An important factor of this equation is the thermal conductivity of the tissues through which the heat is passing. Parry (1949) published the thermal conductivity of dead whale blubber as $0.0005 \mathrm{cal} / \mathrm{cm}^{2} /{ }^{\circ} \mathrm{C} / \mathrm{cm} / \mathrm{s}$ and Kanwisher \& Sundnes (1966) state that conductivity of living tissue is $35-60 \%$ higher. Blubber is an insulation layer and, while useful for measuring heat loss when the whale is trying to conserve heat by contraction of the peripheral blood system, Parry's figure is too low for loss of heat through the black epidermis or lining of the right naris when the whale is actively losing heat by vasodilation. To obtain a more realistic measure of conductivity a selection of tissues 
from the head was freshly collected from sperm whales being flensed at Durban; conductivity of the black epidermis is probably close to $0.0013 \mathrm{cal} / \mathrm{cm}^{2} /{ }^{\circ} \mathrm{C} / \mathrm{cm} / \mathrm{s}$ (Appendix II, Fig. 8).

Returning to other factors in the heat transfer equation, if we take the temperature of the tissue just under the epidermis as $27.5^{\circ} \mathrm{C}$ (see Appendix I), then the distance $(d)$ will be the thickness of the epidermis $(3.6 \mathrm{~mm})$ and the heat lost from the surface of a

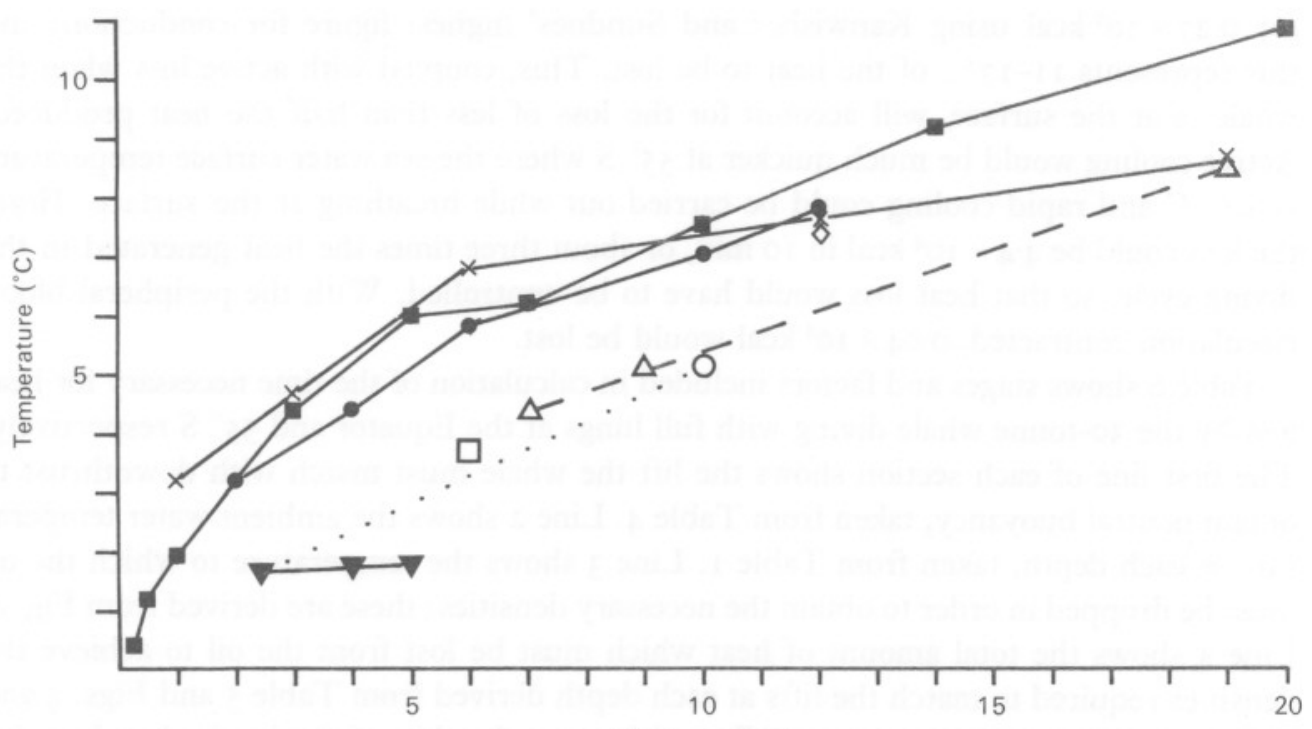

Thickness $(\mathrm{mm})$

Fig. 8. Conductivity measurements of various thicknesses of several tissues from the sperm whale head compared with distilled water (dotted line). For details, see Appendix II. The lefthand scale gives the difference in temperature at equilibrium of two copper plates, one of which was heated and between which the tissue was placed. Open square $=$ wall of the right naris, open triangles = section of case, closed triangles = fluid from lacunae in posterior wall of nasofrontal sinus, closed circles = spermaceti oil tissue from posterior end of sac, closed squares = spermaceti oil from junk, crosses = spermaceti oil from sac, open circle = junk partition material cut across strands, diamond $=$ back of junk spermaceti tissue cut across fibres.

30-tonne whale during the time spent in near surface water at $26^{\circ} \mathrm{C}$ (taking the total surface area including fins and flippers as $74 \mathrm{~m}^{2}$ ) would be

$$
\frac{0.0013 \times 74 \times 10^{4}(27.5-26.0) \times 60}{0.36 \times 1000}=240 \mathrm{kcal} / \mathrm{min},
$$

or a total of only $2400 \mathrm{kcal}$ in $10 \mathrm{~min}$. As the energy used on a dive probably exceeds $1.0 \times 10^{4} \mathrm{kcal}$ (p. 56), this represents $24 \%$ of the exchange necessary in a dive cycle and it would seem that in the tropics most of the loss from the skin must be done after descent below the thermocline (at $100-200 \mathrm{~m}$ ) where the ambient temperature is much lower. (The wrinkles in the blubber (Clarke, 1978a) would only increase the exchange by $7 \%$; as the blubber decreases in volume under pressure the wrinkles probably reduce in area as the pressure increases, but because this probably varies according to depth, the $7 \%$ extra has not been added to the area in calculations of heat exchange.)

It is therefore unlikely that vasoconstriction occurs at the point of submergence and 
vasodilation occurs at the point of surfacing, as found in seals and some cetaceans (Scholander, 1940; Irving et al. 1963), because the total loss by conduction in $50 \mathrm{~min}$ through the whole blubber of the whale in water at $4{ }^{\circ} \mathrm{C}(1000 \mathrm{~m}$ on the Equator) with no help from the blood circulation would be

$$
\frac{0.0005 \times 74 \times 10^{4} \times 25 \times 60 \times 50}{16.3 \times 1000}=0.17 \times 10^{4} \mathrm{kcal} \text { in } 50 \mathrm{~min} \text { at } 1000 \mathrm{~m} \text {, }
$$

(or $0.27 \times 10^{4} \mathrm{kcal}$ using Kanwisher and Sundnes' highest figure for conduction) and this represents $11-17 \%$ of the heat to be lost. This, coupled with active loss when the whale is at the surface, will account for the loss of less than half the heat produced. Active cooling would be much quicker at $55^{\circ} \mathrm{S}$ where the sea water surface temperature is $1.5{ }^{\circ} \mathrm{C}$ and rapid cooling could be carried out while breathing at the surface. Here, the loss could be $4.4 \times 10^{4} \mathrm{kcal}$ in $10 \mathrm{~min}$, or about three times the heat generated in the diving cycle, so that heat loss would have to be controlled. With the peripheral blood circulation contracted, $0.04 \times 10^{4} \mathrm{kcal}$ would be lost.

Table 6 shows stages and factors included in calculation of the time necessary for heat loss by the 30-tonne whale diving with full lungs at the Equator and $55^{\circ} \mathrm{S}$ respectively. The first line of each section shows the lift the whale must match with downthrust to obtain neutral buoyancy, taken from Table 4 . Line 2 shows the ambient water temperature at each depth, taken from Table 1 . Line 3 shows the temperature to which the oil must be dropped in order to obtain the necessary densities; these are derived from Fig. 4 . Line 4 shows the total amount of heat which must be lost from the oil to achieve the densities required to match the lifts at each depth derived from Table 5 and Figs. 4 and 5. Line 5 shows the temperature differential across the skin of the head when blood is actively helping loss of heat by vasodilation. This is taken as $27.5^{\circ} \mathrm{C}$, minus the ambient temperature (see Appendix I). Line 6 shows the heat loss from the skin of the head while the skin capillaries are dilated at each depth. This is calculated from formula 1, for heat loss (p. 33), using the temperature differential in line $5,24.3 \mathrm{~m}^{2}$ as the area of the head, 0.0013 as the coefficient of conduction and $0.36 \mathrm{~cm}$ as the distance $(d)$ or thickness of the skin. Line 7 shows the time in minutes necessary to lose the heat required and is found by dividing values of line 4 by those of line 6 (Fig. 9). Lines 8-10 give similar information to lines 5-7, but for loss of heat from the right naris instead of from the skin of the head. The surface area of the right naris is taken as $4.7 \mathrm{~m}^{2}$ (Clarke, 1978a) and the distance $(d)$ is taken as $0.1 \mathrm{~cm}$, which was the thickness of the connective tissue separating the fatty-vascular tissue from the lumen of the right naris in several samples from several whales. This thickness varies over the length and tends to be less over the broadest region at the posterior end, where it may be as little as $0.06 \mathrm{~cm}$ thick. The temperature differential is the mean of $33^{\circ} \mathrm{C}$ and the temperature the spermaceti must be to match the lift (line 3) minus the ambient water temperature.

Line 11 shows the time necessary to lose the heat, which has to be lost for neutral buoyancy (line 4) via the skin of the head and the right naris together. Line 12 is the temperature differential across the blubber, supposing the blood vessels outside the blubber are contracted. The temperature just below the blubber has been measured as $29^{\circ} \mathrm{C}$ immediately after capture (Appendix I) and the difference between this and the 
Table 6. Time required to lose the heat necessary to cool the spermaceti oil to obtain a change in density sufficient to balance lift at various depths on the Equator and at $55^{\circ} \mathrm{S}$

Whale neutrally buoyant at the surface after exhalation on the Equator and dives with lungs full.

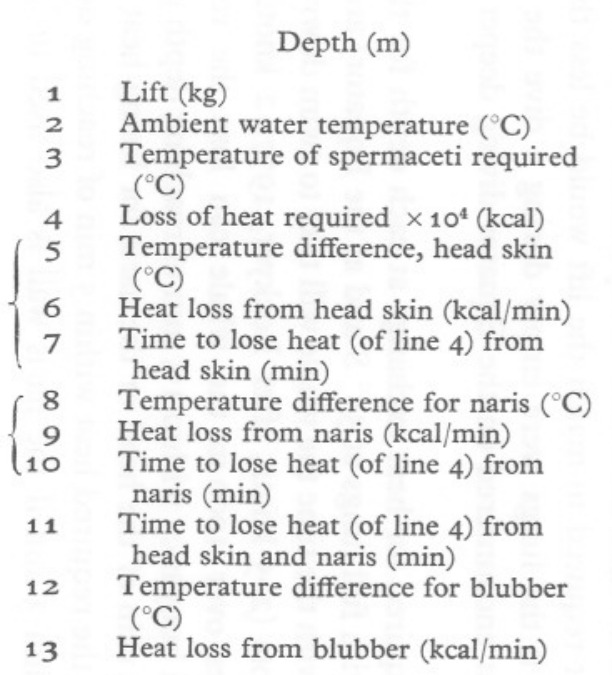

\begin{tabular}{cccc}
\multicolumn{4}{c}{ Equator } \\
200 & 500 & 1000 & 1500 \\
9 & 13 & 25 & 42 \\
13.1 & 6.4 & 4.3 & 4.2 \\
30.3 & 30.1 & 31.3 & 29.8 \\
0.42 & 0.54 & 0.64 & 0.78 \\
14.4 & 21.1 & 23.2 & 23.4 \\
758 & 1111 & 1221 & 1232 \\
5.5 & 4.9 & 5.2 & 6.3 \\
18.6 & 25.1 & 27.9 & 27.3 \\
682 & 920 & 1022 & 1001 \\
6.2 & 5.9 & 6.3 & 7.8 \\
2.7 & 2.7 & 2.9 & 3.5 \\
15.9 & 22.6 & 24.7 & 24.8 \\
34.7 & 49.3 & 53.8 & 54.0
\end{tabular}

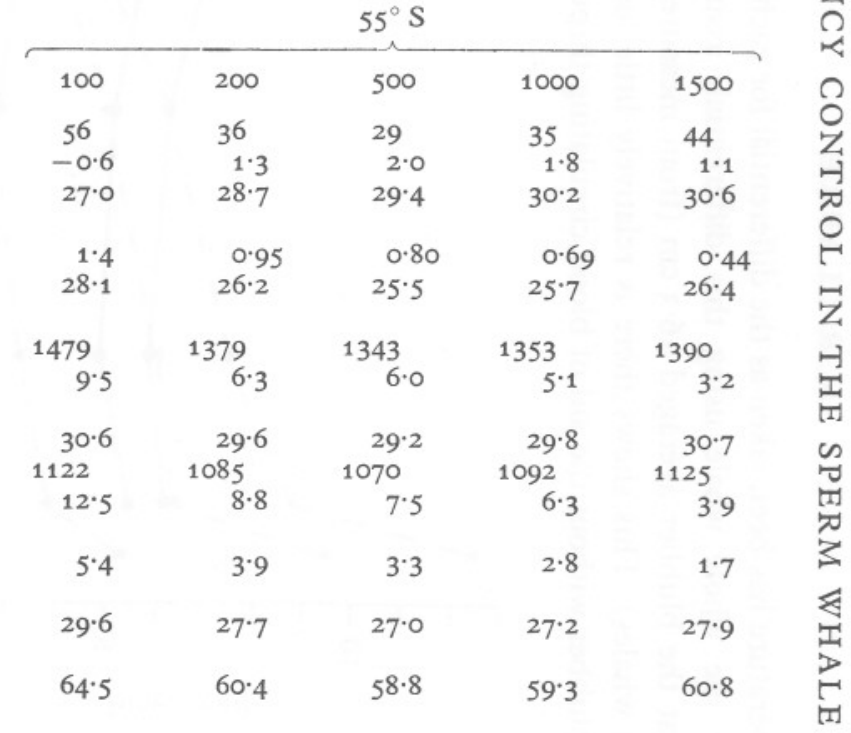


ambient temperature has been taken as the differential for each depth. Line 13 gives the heat loss for the whole whale using this differential, assuming a surface area of $74 \mathrm{~m}^{2}$ and that the blubber averaged $16.3 \mathrm{~cm}$ (from measurements at many positions over the four whales). This shows there is relatively little loss of heat by conduction through the blubber without the aid of blood circulating through the epidermis.

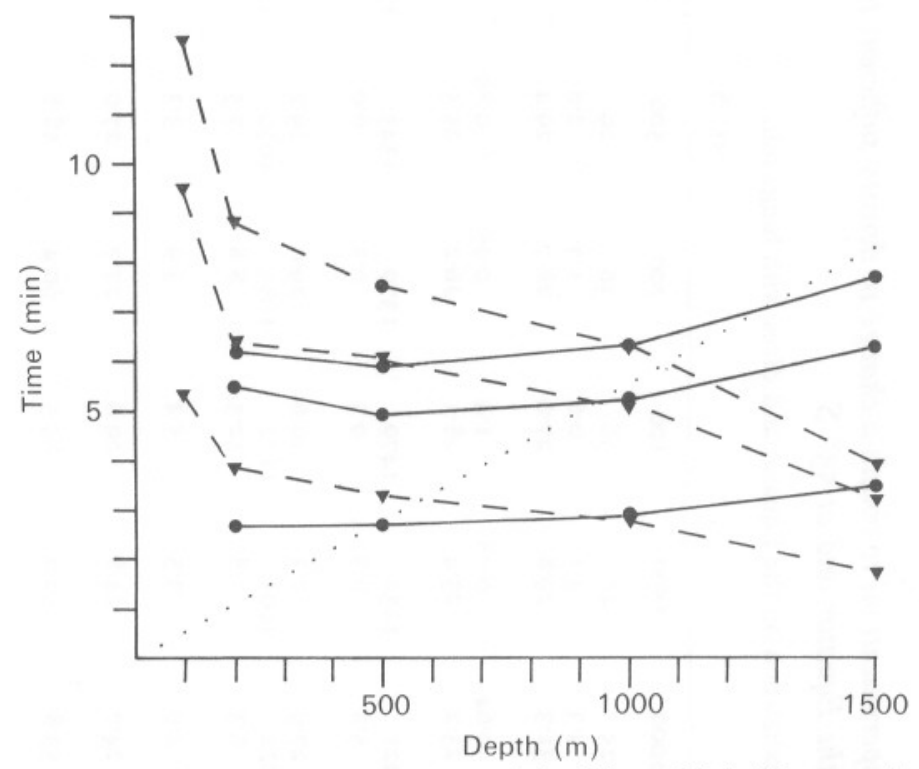

Fig. 9. The time required for a 30-tonne sperm whale diving with full lungs to lose sufficient heat from its spermaceti in order to achieve neutral buoyancy at successive depths on the Equator (circles) or at $55^{\circ} \mathrm{S}$ (triangles) assuming it is neutrally buoyant after exhalation at the surface on the Equator. Dotted line shows the time to reach each depth if the whale swims down at 5 knots. For each region there are three traces: the upper trace is for the naris alone losing heat; the middle is for the head surface losing heat and the lower is for the naris and head surface losing heat together.

The situation on the Equator if the whale dives with lungs empty is not considered in Table 6 since downthrust would be experienced to $500 \mathrm{~m}$ and, at $1000 \mathrm{~m}$ and deeper, the loss of heat required to match the lift would be less than with lungs full (Fig. 6). Also, at $55^{\circ} \mathrm{S}$ if the lungs were empty during a dive the whale would face less of a problem to that encountered on the Equator diving deeper than $200 \mathrm{~m}$ with full lungs (see Fig. 6).

The time required for heat exchange at each depth for the two alternatives in Table 6 (i.e. diving with full lungs at $55^{\circ} \mathrm{S}$ and at the Equator) are summarized in Fig. 9, and are compared with the time the whale will take to swim down to each depth at its cruising speed of 5 knots (2-5 knots, after Lockyer, 1977; 2 knots, after Watkins \& Schevill, 1977). In dives over $1000 \mathrm{~m}$ the whale can lose the required amount of heat to achieve neutral buoyancy within $1.5 \mathrm{~min}$ of reaching depth or on the way down whether it uses just the skin of the head or the naris for losing heat. In dives to $200-1000 \mathrm{~m}$ the whale can lose the required heat within $5 \mathrm{~min}$ of reaching depth via the skin of the head alone, and within $3 \mathrm{~min}$ if the naris wall is also used to lose heat. At $55^{\circ} \mathrm{S}$ the time 
needed to lose sufficient heat at $100 \mathrm{~m}$ using either the right naris or the skin of the head is about a fifth of the dive time and possibly too long to justify becoming neutral. However, in the Antarctic cold surface water the temperature of the spermaceti oil might be kept permanently lower than $33^{\circ} \mathrm{C}$ (its temperature at the surface at Durban) and cooling could then be rapid to obtain neutral buoyancy at depth.

Another factor in determining the time required for lowering the spermaceti temperature is the time required for the actual phase change. While this is certainly not instantaneous with heat removal, the heating curves from which the quantity of heat was calculated were obtained by a paper speed of $3 \mathrm{~cm} / \mathrm{min}$ or $8{ }^{\circ} \mathrm{C} / \mathrm{min}$ (Clarke, 1978b). As the greatest drop in temperature is less than $6^{\circ} \mathrm{C}$ and, as either heat exchange or the descent at 5 knots requires more than $2 \mathrm{~min}$, the speed of the phase change cannot be long enough to greatly affect the calculation.

Having established that considerable heat can be lost through the surface of the right naris, it is now necessary to see if enough water can conveniently be passed through the right naris to remove the heat. The capacity of the right naris if it is filled to a cylindrical shape is 3731 in a 30-tonne whale (Clarke, 1978a). This has a heat capacity of near to $373 \mathrm{kcal}$ per $1{ }^{\circ} \mathrm{C}$. Thus, to remove $1.4 \times 10^{4} \mathrm{kcal}$ (the most heat it would be necessary for it to lose, Table 6) would require

$$
\frac{1.4 \times 10^{4}}{3.73 \times 10^{2} \times 15}=2.5
$$

fillings of the right naris. Because this would halve the temperature difference (which is taken as $15^{\circ} \mathrm{C}$ instead of $33.2{ }^{\circ} \mathrm{C}$, the initial differential) between the fat and the water, it would double the time taken to lose the same amount of heat from the naris and the total time required using the head skin and naris would be changed from 5.4 to $6.9 \mathrm{~min}$. As pointed out above, at $55^{\circ} \mathrm{S}$ the whale might overcome this difficulty by partly cooling its snout at the surface, thereby reducing the time necessary for cooling at depth.

At $200 \mathrm{~m}$ and deeper, two fillings or less would be sufficient and the increase in time due to halving the temperature differential would be of little consequence. At these depths the heat loss through either the head surface or the right naris would be adequate for achieving neutral buoyancy.

Thus, even when the maximum heat needs to be lost it can be done in less than 3 pumps of the right naris. However, as noted previously (Clarke, 1978a), the wall of the right naris will easily stretch to 1.25 times its original width and will increase the volume accordingly.

If, as seems possible, the left naris is involved in pumping, it would only require 9-15 pumps to fill the right naris three times.

The work done in moving the water into and out of the right naris would equal approximately $8.7 \times 10^{4} \mathrm{~J}$ if three times the volume of the right naris was pumped via the left naris at an acceleration equivalent to gravity (it is likely to be less than this). This is equivalent to $21 \mathrm{kcal}$, or $104 \mathrm{kcal}$ allowing for $20 \%$ efficiency, an insignificant quantity compared with the energy available to the whale (p. 56). 


\section{Heat available for reheating the spermaceti oil}

All the energy used by animals is converted to heat so that an estimation of the energy available to the whale may be taken as an estimation of heat produced by movement and other activities.

An estimate of energy available on a dive can be made from the consumption of food by Cetacea in captivity. As sperm whales have not been studied in captivity, a direct measure cannot be made, but Sergeant (1969) concluded that large Balaenoptera (rorquals) consume $3.5 \%$ of their body weight per day. His data for sperm whales are inadequate, but they are likely to be similar to rorquals and the weight of flesh consumed per day is probably close to this value. If we accept this value, the 30-tonne whale would eat $1050 \mathrm{~kg}$ of food each day.

Muscular loliginid squid are often used for feeding Cetacea in captivity and, taking the calorific value of raw squid as $840 \mathrm{kcal} / \mathrm{kg}$ (Altmann \& Dittmar, 1968), the calories consumed each hour would be $3.7 \times 10^{4} \mathrm{kcal}$. As this would provide energy for the nondiving, less active, period of the day, including sleeping, the energy available per dive would probably exceed $3.7 \times 10^{4} \mathrm{kcal}$. If we take $2.5 \%$ of the body weight as a minimum value for food consumed per day, then more than $2.6 \times 10^{4} \mathrm{kcals}$ would be available on each dive.

A second estimate of the energy available for each dive may be derived from the amount of oxygen breathed in while at the surface between dives.

The number of breaths between deep dives is very regular for large bull whales; 5060 breaths are taken in the $10 \mathrm{~min}$ between surfacing and sounding (Scoresby, 1820). The lung volume for a $44 \mathrm{ft}$ whale is probably near 7001 (Clarke, 1978a) and the tidal volume is $85 \%$ of the lung volume.

Thus for each deep dive, $60 \times 700 \times 0.85=3.6 \times 10^{4} 1$ of air or $3.6 \times 10^{4} \times 0.2=$ $7 \cdot 2 \times 10^{3} 1$ of oxygen are breathed. If they are the same as Tursiops (Ridgway, Scronce \& Kanwisher, 1967) and Phocaena (Irving, Scholander \& Grinnell, 1941), the oxygen used by sperm whales at each breath equals $7-10 \%$ of the lung volume, so that $700 \times$ $60 \times 0.07$ (or 0.1$)=2940$ (to 4200 ) 1 of oxygen are available to oxidize available food stores during each dive. As a litre of oxygen liberates approximately $5 \mathrm{kcal}$, the energy available is $1.5 \times 10^{4}$ to $2 \cdot 1 \times 10^{4} \mathrm{kcal}$.

A useful comparison of the above value for oxygen consumption with pulse rate can be made, Kibler \& Brody (1943) published the relationship between oxygen consumption, rate of heart beat and body weight of a wide size range of animals. They showed that

$$
\text { pulse rate }(\text { frequency } / \mathrm{min})=\frac{\text { oxygen consumed }(\mathrm{cc} / \mathrm{min})}{\text { body weight }(\mathrm{kg}) \times 0.05} \text {. }
$$

As, during diving, the whale only breathes 60 times $/ \mathrm{h}$, the oxygen consumed by the whale can be taken as $49 \mathrm{l} / \mathrm{min}$.

The pulse rate is therefore

$$
\frac{49 \times 10^{3}}{30000 \times 0.05}=33 \text { beats } / \mathrm{min}
$$


Measurements of pulse rate in large Cetacea were made by White, who recorded $16-17 / \mathrm{min}$ in a submerged Beluga (see Slijper, 1962) and by Kanwisher \& Senft (1960), who recorded $25 / \mathrm{min}$ in a stranded fin whale. This suggests that this estimate of pulse rate, and hence of the oxygen consumed, is possibly a little too high.

A third estimate of the energy available during a dive may be made from the oxygen capacity of the body. Scholander (1940) derived the values for a bottlenose whale (on the left of Table 7) and values for the 30-tonne sperm whale have been made by taking $10 \%$ for lung air utilization, $12 \%$ of body weight for the volume of blood and tissue fluids together (Gambell, 1972) and $34 \%$ of body weight for the weight of muscle (Omura, 1950). This suggests an oxygen capacity of 17351 giving a calorific value of $0.87 \times 10^{4} \mathrm{kcal}$.

Table 7. Estimates of the oxygen stored during a dive of a Bottlenose whale (from Scholander, 1940) and a sperm whale

\begin{tabular}{lrll} 
& Bottlenose & \multicolumn{2}{c}{$30 \mathrm{ft}$ sperm whale } \\
401 of lung air at $15 \%$ utilization & $=61$ & 7001 at $10 \%$ & $=701$ \\
$15 \%$ blood at $25 \%$ utilization & $=451$ & 36001 at $25 \%$ & $=9001$ \\
$725 \mathrm{~kg}$ flesh at $7.5 \%$ utilization & 541 & $10200 \mathrm{~kg}$ at $7.5 \%=7651$ \\
$70 \%$ tissue fluid at $0.5 \%$ utilization & $=41$ & & \\
$\quad$ Total oxygen stored & 1091 & & 17351
\end{tabular}

Benedict (1938) published a curve relating body weight and the basal metabolic heat of a wide size range of mammals. Extrapolation of his curve gives a value of $1.3 \times 10^{5}$ $\mathrm{kcal} /$ day for a 30-tonne whale or a basal production of $0.54 \times 10^{4} \mathrm{kcal} / \mathrm{h}$. Kanwisher \& Sundnes (1966) found that Benedict's curve did not hold for a small cetacean in cold water which had a much higher basal rate. As a mammal could maintain more than four times its basal metabolic rate for an hour of exercise, a total production of at least $2.0 \times 10^{4} \mathrm{kcal}$ might be expected.

Finally, a fifth estimate of the heat produced during a $1 \mathrm{~h}$ dive can be made by estimating the energy used by a sperm whale during swimming. Although many uncertainties still remain in our knowledge of cetacean swimming, a rough estimate of the power exerted by a whale swimming at constant velocity may be calculated from

$$
\text { power }=\frac{1}{2} \rho A C_{f} V^{3},
$$

where $\rho=$ density of sea water, $A=$ the whale's surface area in $\mathrm{cm}^{2}, V=$ the speed in $\mathrm{cm} / \mathrm{s}$ and $C_{f}=$ the surface friction drag coefficient.

The drag coefficient will vary with the amount of turbulence in the boundary layer of the swimming whale. Kermack (1948) and Hill (1950) adopted the formula of Prandtl for turbulent flow and that of Blasius for laminar flow. These were respectively

and

$$
C_{f}=0.455\left(\log _{10} R e\right)^{-2.58} \text { for turbulent flow }
$$

$$
C_{f}=1.33 R e^{-0.5} \text { for laminar flow. }
$$

$R e$ in these formulae is the Reynold's number

$$
R e=\frac{V L}{v},
$$


where $V=$ velocity, $L=$ length and $v=$ kinematic viscosity of the ambient water, which is the dynamic viscosity divided by the density. A typical value of $v$ of sea water at $5^{\circ} \mathrm{C}$ is $10^{-2} \mathrm{~cm}^{2} / \mathrm{s}$, so that $R e$ is approximately $3.4 \times 10^{7}$ for the 30 -tonne $(13.4 \mathrm{~m})$ sperm whale travelling at 5 knots. This gives a $C_{f}$ value for turbulent flow of 0.0025 and for laminar flow of 0.00023 .

Applying these to the formula for calculating resistance or force at 5 knots:

drag if the whale has only turbulent flow

$$
\begin{aligned}
& =\frac{1}{2} \times 1.025 \times(250)^{3} \times 74 \times 10^{4} \times 0.0025 \\
& =1.5 \times 10^{10} \mathrm{ergs} / \mathrm{s}=1500 \mathrm{~W} \\
& =1290 \mathrm{kcal} / \mathrm{h} \text { for turbulent flow or } 117 \mathrm{kcal} / \mathrm{h} \text { for laminar flow. }
\end{aligned}
$$

The widest part of the body is $32 \%$ of the length from the front (the average of the four whales which were measured for blubber area in Clarke, 1978a). From studies on fish locomotion (Alexander, 1971) it may be assumed $32 \%$ of the body has laminar flow and $68 \%$ turbulent flow over its surface and the power necessary would be $1060 \mathrm{~W} \equiv$ $911 \mathrm{kcal} / \mathrm{h}$.

If we make the further assumption that the whale has an overall efficiency of $20 \%$ (Hill, 1950), the energy it will use in swimming continuously at 5 knots for $1 \mathrm{~h}$ will be $0.46 \times 10^{4} \mathrm{kcal}$. When swimming, it will also need $0.54 \times 10^{4} \mathrm{kcal}$ for basal metabolism as well as extra energy for extra blood circulation, etc., so that the total energy used will be in excess of $1.0 \times 10^{4} \mathrm{kcal}$ during a diving cycle. This calculation is only made to estimate the amount of energy which could be used in the hour of a dive. Of course, if the whale lies still at depth it might use rather less for swimming, but it might be necessary for it to divert excess energy into other processes or into short-period bursts of faster activity.

Bringing together our five estimates of heat produced during a diving cycle, we have from

(1) the food consumed:

(2) the oxygen breathed:

(3) the oxygen capacity of the body:

$2 \cdot 6-3 \cdot 7 \times 10^{4} \mathrm{kcal}$

(4) body weight to basal metabolism:

$1 \cdot 5-2 \cdot 1 \times 10^{4}$

(5) work done if swimming continuously:

$0.9 \times 10^{4}$

$>2 \cdot 0 \times 10^{4}$

$1.0 \times 10^{4}$

From these it would seem likely that the estimate of oxygen capacity of the body is low. However, the food consumed might give rather an overestimate of energy on a dive, since during the period the whale is not undertaking deep feeding dives it probably breathes much more than 60 times in an hour and can therefore use rather more of its food reserves. The last two estimates may be high since the whale moves rather little laterally during a deep dive (p. 29). However, it would appear likely that the whale produces at least $1 \cdot 0-1 \cdot 5 \times 10^{4} \mathrm{kcal}$ of heat during a typical deep dive cycle.

In considering the heat available for buoyancy control, the heat loss by conduction via the blubber of the whole surface must be subtracted from the total heat available. This is given for different depths in Table 6, line 13. At its greatest, this is $64.5 \mathrm{kcal} / \mathrm{min}$, which in $60 \mathrm{~min}$ in the cold water at $55^{\circ} \mathrm{S}$ would amount to $0.39 \times 10^{4} \mathrm{kcal}$. If all the 
remaining heat can be used for recovery after obtaining buoyancy, and there seems little reason to believe it cannot, then the heat available would be 0.6 to $1.1 \times 10^{4} \mathrm{kcal}$.

Fig. 6 shows the heat required to raise the temperature of the spermaceti oil from its temperature at neutral buoyancy at each depth to its temperature at the surface $\left(33^{\circ} \mathrm{C}\right)$. If the estimate of $0.6-1.1 \times 10^{4} \mathrm{kcal}$ for the heat available is correct there would be insufficient heat for the whale to recover after becoming neutrally buoyant at $100 \mathrm{~m}$ at $55^{\circ} \mathrm{S}$, if it dives with full lungs. However, in the colder surface water at $55^{\circ} \mathrm{S}$ the whale could readily cool the spermaceti prior to leaving the surface or keep it permanently at a lower temperature than at Durban so that it could match downthrust at $100 \mathrm{~m}$. On the other hand, if it dives after exhaling, sufficient heat would be available.

Thus, sufficient heat is available for buoyancy control of the kind suggested.

\section{Storage of heat}

In order for the body heat to be used in heating the spermaceti over a brief period, it would need to be stored in the body, principally the muscles. Therefore, possibly $1.5 \times 10^{4} \mathrm{kcal}$ would be stored in the body, mainly the swimming muscles, before loss from the whale. As the weight of muscle is $34 \%$ of the body weight for a $13.7 \mathrm{~m}$ whale (Omura, 1950), $10200 \mathrm{~kg}$ of muscle is available to store the heat. As the specific heat of muscle is 0.75 (from dead mammals), the rise in temperature of the muscle would be

$$
\frac{1.5 \times 10^{4}}{1.02 \times 10^{4} \times 0.75}=2{ }^{\circ} \mathrm{C} \text {. }
$$

Such a rise in muscle temperature could easily be tolerated.

\section{Timing of heat loss}

General pattern. At the Equator the heat produced in a diving cycle could not be lost during the $10 \mathrm{~min}$ near the sea surface because, shallower than $100 \mathrm{~m}$, there is less than $2 \cdot 6^{\circ} \mathrm{C}$ between the ambient water temperature and the temperature beneath the skin of the whale. Active loss of heat by vasodilation at the surface and passive loss at depth will only lose a small proportion of the heat produced during the hour of the diving cycle (the deficit is shown in Fig. 10, alternative F). Thus, extensive vasoconstriction during the submerged 50 min of the dive cannot take place as in many other diving mammals (Scholander, 1940) because part of the time in cold water must be used for heat loss.

Heat produced in excess of that lost by passive conduction can either be lost slowly by controlled, partial vasodilation to keep pace with heat production, or be lost by greater vasodilation over a restricted period or periods during the dive. The latter method would require less prolonged and accurate control and would permit the whale both to maintain some reserve of heat within the body and to use the spermaceti oil for buoyancy control in the manner suggested here. During the descent, the spermaceti would be cooled by loss of heat through the skin and probably the right naris. Upon matching the lift, soon after reaching the selected depth, vasoconstriction would stop active cooling of the spermaceti oil. Minor adjustments to buoyancy could be made by passing small quantities of water into the right naris without vasodilating and consequent general active loss of heat over the head, or head and body, surface. During most of the time at 
depth the body, particularly the muscles, would increase in temperature. Just prior to the ascent from depth, blood supply to the snout would be expanded so that more blood would enter the spermaceti organ and would carry in heat from the body. The oil could be rapidly heated to $33^{\circ} \mathrm{C}$ at the same time as lowering the body temperature to normal. Heating of the oil would lower its density and the whale would be lifted (or helped) towards the water surface even if it were exhausted (i.e. as far as $200 \mathrm{~m}$ depth). Heat in excess of that required to warm up the spermaceti could then be lost via the body surface.

Vasoconstriction and vasodilation. Alternatives in timing and loss of heat will now be considered in more detail assuming that the temperature of the spermaceti is lowered to achieve neutral buoyancy.

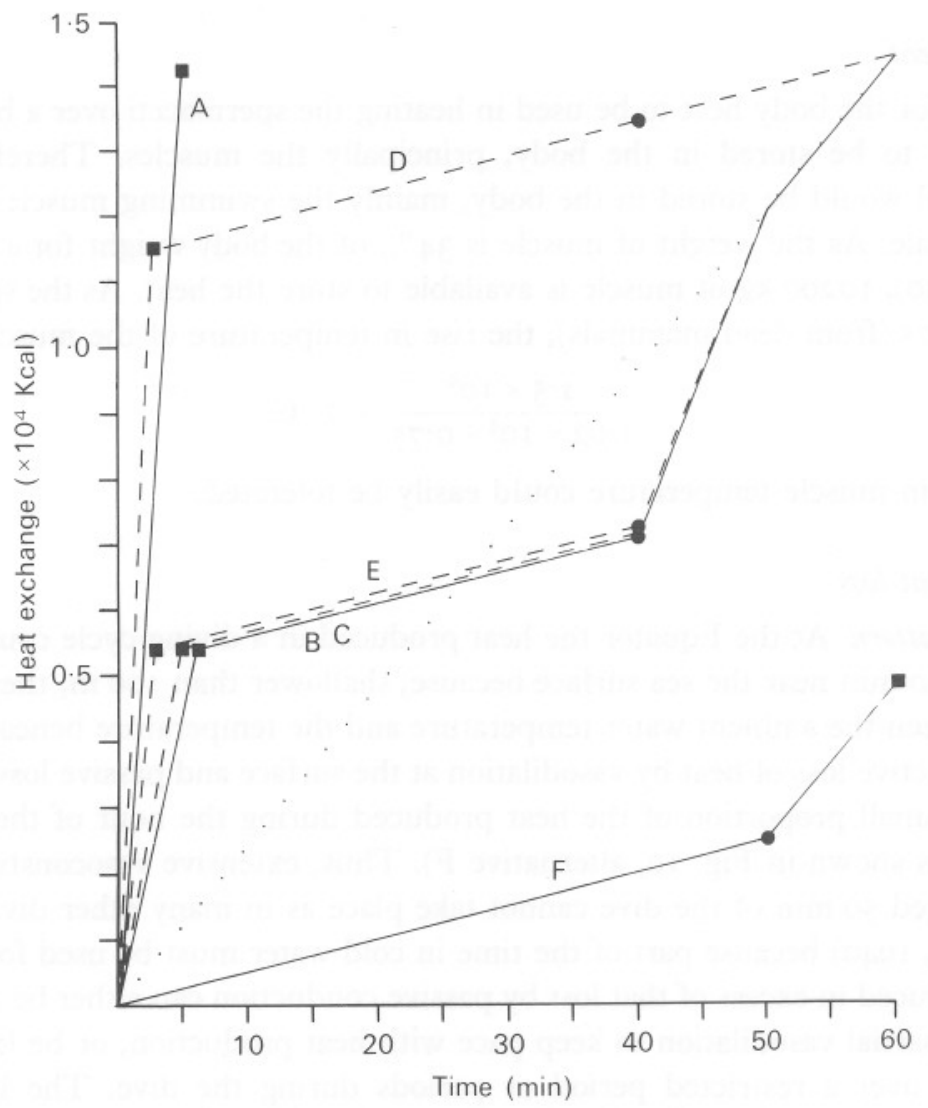

Fig. 10. The timing of heat loss from a 30 -tonne whale diving with lungs full to $500 \mathrm{~m}-\mathrm{six}$ alternatives. Squares $=$ vasoconstriction. Circles $=$ vasodilation. (A) Heat is lost through the whole body and head surface and the right naris is not used. General vasoconstriction is delayed until neutral buoyancy is achieved. (B) Heat is lost only from the surface of the head until neutral buoyancy is achieved. (C) Heat is lost only from the right naris until neutral buoyancy is achieved. (D) Heat is lost from the skin of the whole body and head surface and also through the right naris until neutral buoyancy is achieved. (E) Heat is lost from the head surface and the right naris until neutral buoyancy is achieved. (F) If the whale vasoconstricted and vasodilated only at the sea surface insufficient loss of heat could be achieved to permit a succession of long dives with only $10 \mathrm{~min}$ between them. The dotted line indicates the cumulative production of heat during the cycle assuming a constant rate. 
'Active' cooling of the head via the skin may involve vasodilation of the head alone. Such a regional dilation is similar to facial 'blushing' of humans but the possibility of this in sperm whales has not been established. Some whales at Durban showed distinct dilation of dermal papillae on the head with blood after capture (p. 44) but, when the body was also checked, similar dilation was also found (personal observations). Felts (1966), partly on the basis of Kanwisher's work, asserts that the heat control function of the cetacean extremities is not necessarily total organ in scope, but, rather that localized parts may be used as the physiological state requires.

To show alternative timing, a 30-tonne whale diving to $500 \mathrm{~m}$ on the Equator with lungs full will be taken as an example.

Table 8. Temperatures read with a thermistor probe inserted into the snout of a sperm whale immediately after death in ${ }^{\circ} \mathrm{C}$

The temperatures were read one after another nine times taking a total of about $10 \mathrm{~min}$.

\begin{tabular}{|c|c|c|c|c|c|c|c|c|c|c|}
\hline \multirow[b]{2}{*}{$\begin{array}{c}\text { Thermistor } \\
\text { no. }\end{array}$} & & \multicolumn{9}{|c|}{ Depth } \\
\hline & & 1 & 2 & 3 & 4 & 5 & 6 & 7 & 8 & 9 \\
\hline 1 & & & & & d not & ction & & & & \\
\hline 2 & Muscle & 28.9 & $29 \cdot 6$ & 30.5 & $30 \cdot 7$ & $31 \cdot 0$ & $31 \cdot 3$ & $31 \cdot 3$ & $31 \cdot 0$ & 32.0 \\
\hline 3 & Muscle & 30.6 & $31 \cdot 2$ & $31 \cdot 6$ & $31 \cdot 8$ & $32 \cdot 2$ & $32 \cdot 1$ & $32 \cdot 1$ & $32 \cdot 2$ & $32 \cdot 4$ \\
\hline 4 & Sac & $32 \cdot 4$ & 32.9 & 33.0 & 32.9 & $33 \cdot 2$ & 33.4 & 33.4 & 33.4 & 33.4 \\
\hline
\end{tabular}

As a first possibility, let us assume vasoconstriction of the whole skin takes place when the whale has reached $500 \mathrm{~m}$ and achieved neutral buoyancy (Fig. 10, alternative A). Heat will be lost over the whole surface $(3 \times$ the head surface) during descent and the total loss will about equal the total heat produced over the dive cycle (taking $1.5 \times 10^{4}$ $\mathrm{kcal}$ ). When this is added to passive loss through the blubber of the whale (Fig. 10F) more heat would be lost than is produced. We can therefore discount this alternative.

Secondly, let us assume vasoconstriction in the skin of the body and the head occurs at submergence and almost all the loss of heat from the spermaceti oil is via the naris (Fig. 10, alternative B). Then the time taken to match the lift will be longer than if loss were also taking place through the skin, but it would still only be $5.9 \mathrm{~min}$ or $12 \%$ of the dive time. Before the ascent, dilation of the blood vessels of the spermaceti tissue could shunt heat from the body until the temperature was $33^{\circ} \mathrm{C}$ and then the rest of the heat produced would be lost through the body surface after general dilation of the skin blood vessels. Indeed, in this alternative there would be plenty of heat for dilation of the blood vessels of the spermaceti and the entire skin to take place simultaneously so that it is unnecessary to postulate independent action which is required in the first alternative.

Thirdly, we can postulate that blood vessels of the body skin constrict at submergence while those of the head skin only constrict after the spermaceti oil has been cooled to match the lift at depth (Fig. 10, alternative C). This would cool the spermaceti more rapidly than in alternative $\mathrm{B}$ but requires the assumption that the whale can vasoconstrict blood vessels in the head and body independently.

Fourthly, if the loss of heat is via the right naris and all the skin the loss would be 
achieved in less time than in the above methods so that rather less heat from the body will be lost to the water at this stage (Fig. 10D).

Fifthly, the most efficient loss would be through the naris together with the skin of the head alone (Fig. 10E).

All but A of these alternatives would be possible, and alternative D does not require the assumption that the skin of the head can dilate separately from that of the body. As there is evidence that the naris is used possibilities B, D or E are the most likely.

\section{Centre of gravity}

If a whale changes the density of its head as suggested, this will move its centre of gravity forwards when the density is increasing during the descent, and backwards when density is decreasing during or just before the ascent. These changes would be advantageous during these parts of the diving cycle, since the whale probably moves almost vertically during the type of dive being considered. However, there would be a difference in trim between the condition at the surface and at depth. The centre of gravity of the whale can be in the best place for swimming at depth, while the relatively large buoyancy of the full lungs would be the main factor in the whale's trim at the surface.

\section{'Popping up' and 'extra' buoyancy}

The 30 -tonne whale with lungs of 7001 would experience a downthrust of about $30 \mathrm{~kg}$ near $100 \mathrm{~m}$ if it dived on the Equator with full lungs (Fig. 1). If it had $30 \mathrm{~kg}$ surplus buoyancy, at the surface after expiration, the whale could avoid this downthrust and could then rise to the surface from any depth without physical effort. However, this extra lift would be carried at all depths and latitudes and the temperature of the spermaceti required to counter lift would be lower and would consequently require much more heat to raise the temperature to $33^{\circ} \mathrm{C}$ again. This makes such large extra lift unlikely but present estimates are not accurate enough to exclude it altogether. In any case the whale would benefit from a helping lift from great depth to $180 \mathrm{~m}$.

\section{Size of whale}

Calculations for a 15- and a 45-tonne whale suggest that the lifts experienced at various depths could readily be countered by the method proposed here. Whales below about $36 \mathrm{ft}(11 \mathrm{~m})$ or 14 tonnes have less spermaceti oil, relative to their size, than larger whales (Clarke, 1978a). This may be because they do not dive as deep (Caldwell, Caldwell \& Rice, 1966) or migrate to such high latitudes and consequently have a smaller variation in water density. Thus a smaller quantity of oil suffices for the compensation of water density.

\section{DISCUSSION}

\section{General conclusions}

The adult sperm whale is neutrally buoyant or just positively buoyant after exhalation at the surface on the Equator. The evidence shows that these whales often lie still in the water at depth and to do this they must be able to control their buoyancy within very fine limits. The thermal properties and quantity of the spermaceti oil provide a means by 
which the whale can exercise such control. By loss of heat from the surface of the head and possibly through the lining of the right naris, the spermaceti oil can be cooled sufficiently to match the lift it encounters at depths greater than $180 \mathrm{~m}$. On the Equator, loss of heat from the spermaceti oil takes place during the descent and at depth, but in the Antarctic the oil may be maintained at a slightly lower temperature than in the tropics or be partly cooled at the sea surface immediately prior to a dive.

Many of the peculiarities in the general and detailed structure of the snout of the sperm whale, the thermal properties of the spermaceti oil, the dimensions of the oil and nares, the whale's buoyancy at the sea surface and observations of the temperature of the spermaceti oil can be explained by recognition that buoyancy control is one of the principal functions of the snout.

While the present work clearly shows the sperm whale could use the spermaceti organ for buoyancy control at depth the only direct evidence is that at Durban, the temperature of the junk was found to be slightly higher than that of the deeper lying sac spermaceti and, in two whales, sulphate was found in the right naris. Final proof must await a measurement of temperature or density of the oil in situ in a diving sperm whale, a difficult but not impossible task.

The bottlenose whale (Hyperoodon) and the pigmy sperm whale (Kogia) both have spermaceti oil and are deep, long divers and it seems probable, in view of the complicated snout of these whales, that they are also using the organ for buoyancy control. However, this can only be shown when much more of their diving habits, structure and dimensions becomes known.

It must be understood that the diving of these whales and the sperm whale is fundamentally different from that of nearly all, if not all, other cetaceans, some of which make rapid excursions to considerable depths. The fin whale, Balaenoptera physalus, for example, can probably dive to more than $500 \mathrm{~m}$ but this is only for a brief period of up to $10 \mathrm{~min}$ and the whale swims continuously and surfaces some distance from its point of submergence. Such whales are faster swimmers than the three deep-divers with spermaceti oil and are clearly not feeding for long periods at depth.

The absence of an obvious heat exchanger with papillae or counter current systems in the wall of the right naris is explained by the very large surfaces available for exchange when such a large fat volume is involved. A big drop in the temperature of the blood is less required than an overall general cooling of the middle of the head; the sea water is much cooler than the fat over most of the whale's range.

The upward bend of the $29-32{ }^{\circ} \mathrm{C}$ temperature lines for spermaceti oil when relative density is plotted against depth (Fig. 4) is important to the whale since greater density change is possible at depths exceeding $1000 \mathrm{~m}$ than would otherwise be possible. The close match between the slopes of these temperature lines, and the slopes of the lines connecting the densities which the spermaceti oil must achieve to make the whale neutrally buoyant, is very striking and provides good circumstantial evidence in support of the hypothesis.

It is interesting that the rate of loss of heat from the right naris is very similar to loss from the surface of the head and may perhaps indicate that the two regions act as alternatives for heat loss in some situations. 
As pointed out by Kanwisher \& Sundnes (1966), the blubber of whales does not need to be as thick for insulation from heat loss alone. They point out that it probably acts as a food reserve and note that 'hydrostatic buoyancy is also a possible function'. Certainly, by compression of the blubber oil under pressure, the lift imparted to the whale by the non-compressibility of its solid components can be partly matched and this may account for the sperm whale having a thicker blubber than some other whales of the same size (e.g. fin and sei whales).

Morris (1975) not only studied the chemical variation in the spermaceti oil from different parts of the junk and sac but also found that melting of different samples took place at slightly different temperatures and over different ranges. Presumably the difference refers to the disappearance of crystals which is only a small part of the range including the large heat exchange associated with freezing (Clarke, 1978b). Such variation is reflected by the difference in heat exchange seen in the samples of the junk and sac oil, the junk samples requiring rather less heat exchange (Clarke, 1978b). This variability may have some significance in heat loss.

\section{Criticism of the buoyancy control hypothesis}

Since the note (Clarke, 1970) outlining the hypothesis described here was published, Ridgeway (1970), Norris \& Harvey (1972) and Schenkkan \& Purves (1973) have criticized certain aspects, some of which were dealt with in a footnote (Ridgeway, 1970) and others of which have been dealt with in this broader treatment.

Ridgeway's suggestion that food taken in during deep feeding dives would cool the whale is true, but if a large enough quantity to cause considerable cooling were taken in, the whale's appetite would be satiated and it would presumably surface without delay. The thickness of, and lack of, blood vessels in the wall of the first stomach would certainly delay equilibration until the whale was rising or at the surface, when the cooling effect would be useful.

Schenkkan \& Purves (1973) concede that the cooling of the spermaceti oil could have a hydrostatic function at depth but do not agree with the mechanism of cooling suggested. They believe, on the basis of their study of a $150 \mathrm{~cm}$ foetus, that there is 'no mechanism for allowing sea water to enter the nares as Clarke (1970) postulates and it seems to be a common misconception that water will enter any tube that is inverted into it'. The method by which water can be taken into the naris has been described on page 45 . Schenkkan \& Purves also stated, 'Nor can we accept that vasodilation is used to cool the spermaceti organ at high pressure. Since the head is not a closed circuit with respect to the blood circulation, vasodilation would result in reduction of the entire body temperature and not just of the head.' As shown above (p. 57), active cooling of the head and body together could be used to cool the spermaceti oil providing the right naris is also used. However, the general circulation of the snout is separate from that of the rest of the body and it would seem likely that the whale can blush in a way which is common experience in man.

These authors also argue that vasoconstriction is more likely to occur at high pressure, because blood is required to fill the 'vast pterygoid air sinuses that are extensions of the cavity of the middle ear'. With no calculations based on volumes of these sinuses or the 
blood, the validity of this argument is impossible to assess although the sinuses can hardly be 'vast' compared with the adult snout. Their other argument for constriction of the blood system of the head at depth rests upon the correctness of their assumption that gas is retained in the right nasal cavities and their hypothesis is not based upon any calculations. In any case, the present hypothesis suggests vasoconstriction does take place at depth but after a slight delay.

Schenkkan \& Purves believe that Kogia, a close relative of Physeter, has insufficient spermaceti oil to use the spermaceti organ for the same purpose as that described here for the sperm whale and they cannot 'accept the idea that homologous structures can have entirely different functions between families, genera or even species throughout the suborder'. Apart from the dubious validity of this last statement, their rejection of the possibility of Kogia using its spermaceti in the same way is supported by no measurements, calculations or details of distribution, all of which are necessary for an assessment of their rejection.

Norris \& Harvey (1972) consider the statement by Clarke (1970) suggesting that spermaceti oil is held in a dense network of capillaries is incorrect. The word 'dense' is admittedly too vague. Certainly, the network was sufficient to colour the spermaceti tissue dark red in some regions (presumably those being actively cooled) in several whales seen by the author at Durban. Large arteries supply both the sac and the junk spermaceti tissue. The fact these authors stress is that oil can be squeezed easily from the tissue, but this merely shows that little besides oil, capillaries and cell walls are present. They also state that 'buoyancy is likely much more easily controlled by other means such as lung collapse or underwater emission by air'. Lung collapse depends upon pressure and cannot be controlled. Emission of air could not control buoyancy over much of the whale's range since deeper than about $600 \mathrm{~m}$ the total volume left in the lungs (14 1) would be insufficient to match the lift (except diving with empty lungs on the Equator, Table 4). When the air was lost, it could not be used again so that minor adjustments to buoyancy at different depths which is possible by temperature control of spermaceti oil could not take place by air control. It is true that extra swimming effort could counter the lift but sperm whales may have behavioural reasons for lying still (e.g for listening).

\section{Compatibility with other theories}

While the present work strongly suggests control of buoyancy is an important function, it does not invalidate arguments for other functions of the spermaceti sac and related structures. Assessing the validity of these arguments will depend upon much more detailed consideration of structure, habits and physical properties of the tissues than has hitherto been published.

In general, the theories concerning function of the spermaceti organ fall into two groups. First, those which suggest that air is drawn into the right naris for various purposes, such as evacuation of the lungs (Raven \& Gregory 1933; Schenkkan \& Purves, 1973), production of sound in several ways (Schenkkan \& Purves 1973; Tomilin, 1957; Berzin, 1972; Bel'kovich \& Yablokov, 1963 according to Berzin, 1972; Norris \& Harvey, 1972), a reserve air supply (Sleptzov, 1952 according to Berzin, 1972) to change the 
centre of gravity (Raven \& Gregory, 1933) or to aid closure of the narial tubes under pressure (Kleinenberg \& Yablokov, 1958). Secondly, those which suggest the oil and the nares in some way focus or aid the production of sound waves (Norris \& Harvey, 1972; Norris, 1975; Bel'kovich \& Yablokov, 1963, according to Berzin, 1972).

Theories involving air in the right naris are partly in conflict with the use of the right naris as a means of cooling the spermaceti oil, but it must be remembered that if the naris were filled with air at the surface, where the volume of air in a 30-tonne whale would be 370 , at depth the volume would be greatly reduced. At only $100 \mathrm{~m}$ it would be 341 $(9 \%)$, which would do little to impair the intake of water. However, such a change in buoyancy would influence calculations relevant to the function proposed here. There is, however, no evidence that air is drawn into the right naris either from the lungs or from the exterior. The direction of the 'blow', which always goes forwards in this species, and the structure of the nares certainly suggest that breathing is entirely through the left naris. Exhalation of air from the right naris as suggested by Schenkkan \& Purves (1973, p. 111) would certainly be obvious to an observer since the structure in the adult whale indicates that such a 'blow' would be directed backwards and this has not been reported.

Most theories which suggest a sound conduction role for the spermaceti oil in no way conflict with the present hypothesis. If they invoke air in the right naris as a reflector (Norris \& Harvey, 1972), they might fall into the same category as theories in the last paragraph but they may involve rather small volumes of air and may have little influence on buoyancy or the passage of water into the right naris at depth.

For example, if the right naris is filled before a dive the buoyancy would rise above that estimated and when the whale dived it would carry extra buoyancy at depth which, in a 30-tonne whale, would only be $18 \mathrm{~kg}$ at $200 \mathrm{~m}$ and $4 \mathrm{~kg}$ at $1000 \mathrm{~m}$. The whale could match an extra lift of that magnitude and the volume of air would not greatly restrict the passage of water in and out of the right naris. If Norris \& Harvey (1972) are correct in their suggestion that the nasofrontal sac contains air to act as a sound reflector, then clearly this area could not be used for cooling, and the time necessary for cooling via the right naris wall would consequently need to be extended by about $10 \%$.

Chemical structure of the lipids in the heads of various cetaceans have been related to possible channelling or focusing of sound by the head tissues (Malins \& Varanasi, 1975). Morris (1975) has shown differences in the amounts and molecular weights of wax esters present in various parts of the spermaceti organ. At present, little is known of the effect this would have on sound velocity but it is possible that these variations would focus sound emitted by the whale. It is suggested the triacylglycerols containing large amounts of acids with low molecular weights, which are particularly associated with the anterior end of the junk, may be important in focusing sound (Malins \& Varanasi, 1975).

Should the sound reflector or sonic focusing theory be found valid for sperm whales, it will be important to find the effect of changes in density of the oil on sound velocity since change in density is the central requirement of the hypothesis proposed here.

The author is extremely grateful to Professor E. J. Denton, F.R.S. for his encouragement, advice and detailed discussion of the buoyancy control hypothesis. He is also greatly indebted to 
Dr Q. Bone for helpful criticism of the manuscript, to Dr P. Best and Dr R. Gambell for kindly making measurements and taking temperatures of freshly killed whales.

The Union Whaling Co. of Durban, South Africa, kindly provided facilities for two months in 1969 and everyone on the Company staff was most helpful, in particular $\mathrm{Mr} \mathrm{L}$. Surmon, $\mathrm{Mr}$ P. Froude, Mr R. Gibson, Mr J. MacDonald, Mr A. Hermansen and Mr H. Karlsen. Mr K. Pinkerton, Mr A. Larsen and other pilots and spotters of the Aircraft Operating Co. kindly gave invaluable information and took the author on several whale-spotting flights.

Dr P. Purves, Dr R. Clarke, Dr P. Herring, Dr F. Culkin, Mr S. G. Brown and Mr M. J. Tucker helped by early discussion of the hypothesis. The author proffers his hearty thanks to all these colleagues.

\section{APPENDIX I. TEMPERATURE OF THE BLUBBER}

Experiment by Dr P. B. Best, 5 March $1971,14.15$ h, at a position off Durban on latitude $29^{\circ} \mathrm{S}$.

Female sperm whale, $33 \mathrm{ft}(10 \mathrm{~m})$ long dived for $10.75 \mathrm{~min}$ to a range of $340 \mathrm{~m}$ at a tilt of $40^{\circ}$ maximum (i.e. depth of $218 \mathrm{~m}$ ) on the sonar immediately before being killed. A piece of blubber approximately $15 \mathrm{~cm}$ square and $7 \mathrm{~cm}$ thick was cut from flank $40 \%$ of distance from tail stock to dorsal fin. Thermometer placed in centre of blubber at two positions and following temperatures were recorded.

(A) Immediately below epidermis $=27 \cdot 5^{\circ} \mathrm{C}$.

(B) Immediately above connective tissue below blubber $=29^{\circ} \mathrm{C}$.

(C) $2 \mathrm{~cm}$ deep into muscle after blubber removal $=29^{\circ} \mathrm{C}$.

(D) Sea temperature collected with bucket $=25^{\circ} \mathrm{C}$ (not confident).

(E) Sea temperature by engine water intake thermostat $=25 \cdot 1{ }^{\circ} \mathrm{C}$.

(F) Air temperature $=24.8^{\circ} \mathrm{C}(45 \mathrm{~min}$ after experiment $)$.

\section{APPENDIX II. CONDUCTIVITY OF WHALE TISSUES}

Tissues whose conductivity was to be measured were transferred to the laboratory after collection from the body of the whale on the flensing platform at Durban whaling station and immediately placed in a conductivity meter. This meter consisted of a broad, thick-walled, Perspex tube $(5 \mathrm{~cm}$ ID, $10 \mathrm{~cm}$ OD) with a thick copper plate on the bottom and a moving copper plunger which was heated electrically (both $1.6 \mathrm{~cm}$ thick). The plunger could be moved in the tube by means of a micrometer so that it could be placed at an accurately measurable distance from the bottom plate. Both plates contained thermistors near their inner faces. Tissue for comparison was placed between the plungers and the top plate was lowered to give a selected thickness of tissue. The electrical heater of the top plate was switched on and measurements of the temperature of the top and bottom plates were taken every 5-10 min until there was neither change in temperatures nor in the difference in temperature of the two plates. Ambient temperatures were taken at the start and finish of each experiment. The temperature difference for each tissue and for each thickness is given in Fig. 8.

Similar measurements were made for distilled water and are plotted in Fig. 8 for comparison. It will be seen from this that the sample of spermaceti oil squeezed from tissue of the sac and the junk and the spermaceti-impregnated tissue from the sac all 
have similar conductivities which are less (higher on the graph) than conductivities of the less fatty tissues. The less fatty tissues included samples of:

(1) The connective tissue of the partitions between blocks of spermaceti of the junk (cut across the strands).

(2) The case connective tissue from below the left naris.

(3) Another part of the case connective tissue.

(4) The black lining of the right naris and all the tissue between it and the fatty spermaceti tissue. This was removed from the dorsal side, half-way along the naris. The whale was $33 \mathrm{ft} 6$ in $(10.2 \mathrm{~m})$ long. The sample was $6.0 \mathrm{~mm}$ thick.

(5) A sample of the aqueous fluid from the lacunae in the posterior wall of the nasofrontal sac.

These were all very similar to water in their conductivity.

Distilled water has a conductivity of $0.00132-0.00147 \mathrm{cal} / \mathrm{cm}^{2} /{ }^{\circ} \mathrm{C} / \mathrm{cm} / \mathrm{s}$ between $0^{\circ}$ and $30{ }^{\circ} \mathrm{C}$. At $30{ }^{\circ} \mathrm{C}$ sea water has a conductivity of $0.001346 \mathrm{cal} / \mathrm{cm}^{2} /{ }^{\circ} \mathrm{C} / \mathrm{cm} / \mathrm{s}$. For the present purposes a conductivity of $0.0013 \mathrm{cal} / \mathrm{cm}^{2} /{ }^{\circ} \mathrm{C} / \mathrm{cm} / \mathrm{s}$ will be taken as the conductivity of non-fatty tissues of the whale.

\section{APPENDIX III. TEMPERATURE OF SPERMACETI OIL}

To measure temperatures simultaneously at six depths in the body of the whale, three thermistor probes were made, each $1 \mathrm{~m}$ in length and of 1 in stainless-steel tubing. Each thermistor was placed into the probe within a transversely inserted tube, so that the glass-covered tip lay exposed in the bottom of a pit on the side of the probe. The six thermistors were arranged at $16 \mathrm{~cm}$ intervals along the probe and could easily be extracted if they were defective. Wires from the thermistors ran within the core of the probe to a rubber-embedded junction box at the base. An arbitrary scale relating to resistance of each thermistor was calibrated against temperature of the thermistor.

Considerable difficulty was experienced in inserting a probe into a freshly killed whale at sea, and two probes were badly bent due to movement of the whale as it lay against the side of the catcher. However, a probe was eventually pushed right into the dorsal head, approximately half-way along the length of the sac, after a very sharp spear had first been used to make a hole in the blubber and case. The probe was inserted immediately afterwards and no sea water entered the small hole during the operation. The measurement was commenced within $5 \mathrm{~min}$ of the death of the whale. The most peripheral thermistor did not function. The second one lying $18.5 \mathrm{~cm}$ within the outer surface of the whale lay in the large muscle which overlies the sac. The third thermistor $34.5 \mathrm{~cm}$ from the surface almost certainly also lay in this muscle, and the fourth thermistor, $50.5 \mathrm{~cm}$ from the surface, lay in the spermaceti sac. Readings were taken continuously, starting with the second thermistor, until nine runs were completed (Table 8) during a total of about $10 \mathrm{~min}$, at which pcint the probe was bent on the ship's side and ceased to function. While the measurements show that the temperature was still rising in the muscle and had probably not completely stabilized at the final reading, the sac temperature had remained stable for four readings and can probably be taken as accurate.

Thirty-four temperatures were taken of the sac and junk, immediately after being 
cut open on the whale platform, using a $40^{\circ} \mathrm{C}$ calibrated thermometer accurate to $0.2{ }^{\circ} \mathrm{C}$ (Table 9). To obtain these, the thermometer was pushed well into the spermaceti tissue. Although these whales had been dead for $20-30 \mathrm{~h}$, having been towed by the catchers and then awaited the flensing operation, the temperatures are remarkably consistent with one another and, surprisingly, with the measurement of the sac of the freshly killed whale $\left(33^{\circ} \mathrm{C}\right)$. This is a function of the low conductivity and very large volume of the oil. Incidentally, the retention of this high temperature is probably not appreciably aided by bacterial action, since the spermaceti oil does not appear to change to any extent even if kept for years at normal temperatures. Bacterial action may attack the tissues

Table 9. Temperatures of the spermaceti sac, the junk spermaceti, and the back muscle of several whales measured with a $40{ }^{\circ} \mathrm{C}$ thermometer accurate to $0.2{ }^{\circ} \mathrm{C}$ immediately after the tissue was cut open

$\mathrm{F}=$ near the front (in the 4 th block of the junk); $M=$ middle of the sac or junk; $\mathrm{B}=$ back of the sac or junk. In no. 10 the block numbered from the front is indicated in parentheses. Numbers in parentheses following the mean values show the number of measurements.

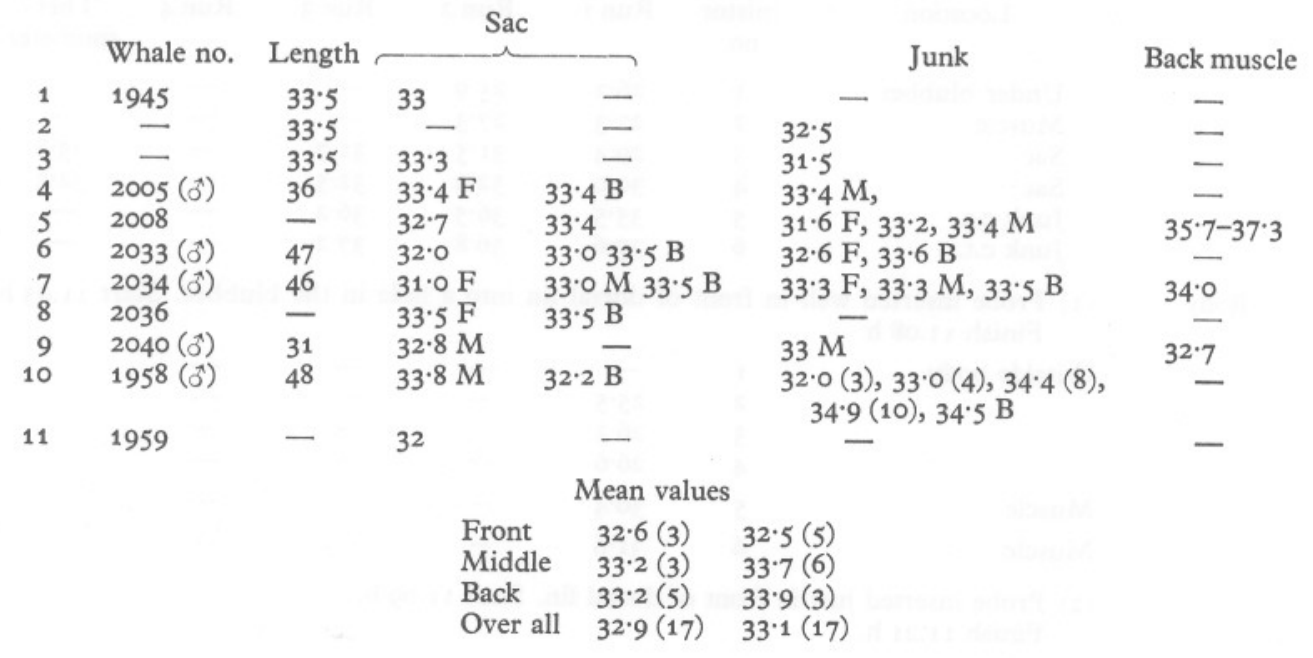

supporting the oil, but these tissues are a small part of the total volume and it is unlikely that sufficient heat could be generated to appreciably warm the oil with its very high heat capacity. Bacterial action, however, probably does warm other tissues of the body after a long post-mortem time.

Another thermistor probe was used to measure temperatures in the sac, the junk and the body of a $48 \mathrm{ft}(14.63 \mathrm{~m})$ sperm whale as it lay on the slipway at Durban, 20-30 h after death (Table 10). These measurements show that the sac had a temperature $3-5{ }^{\circ} \mathrm{C}$ lower than the fibrous connective tissue immediately ventral to it and in the junk. 


\section{APPENDIX IV. SEA WATER IN THE NARIS}

To find whether sea water entered the nares, the lining of these was examined during flensing operations at Durban in 1969. Appreciable quantities of fluid were never found in either naris. Barium chloride solution buffered with hydrochloric acid was poured on the lining of the naris to detect the presence of sulphate which would have indicated the presence of salt water. (Chloride is present in tissues and body secretions and is an unreliable guide to the presence of sea water.)

Table 10. Temperatures of the sac, junk and body of a dead whale no. 1958, length $48 \mathrm{ft}$ $(14.63 \mathrm{~m})$ as it lay on the slipway at Durban (20-30 $\mathrm{h}$ after death) on 24 Aug. 1969.

A probe bearing six thermistors was used for these measurements which were done one after another with as little interval between as possible.

Sac $\quad 6 \mathrm{ft}$ behind blow-hole. Start $10.43 \mathrm{~h}$. Finish $10.57 \mathrm{~h}$.

\begin{tabular}{|c|c|c|c|c|c|c|}
\hline \multirow[b]{2}{*}{ Location } & \multirow{2}{*}{$\begin{array}{c}\text { Ther- } \\
\text { mistor } \\
\text { no. }\end{array}$} & \multicolumn{5}{|c|}{ Temperature $\left({ }^{\circ} \mathrm{C}\right)$} \\
\hline & & Run 1 & Run 2 & Run 3 & Run 4 & $\begin{array}{l}\text { Ther- } \\
\text { mometer }\end{array}$ \\
\hline Under blubber & 1 & $26 \cdot 2$ & 25.9 & - & - & 一 \\
\hline Muscle & 2 & $27 \cdot 3$ & $27 \cdot 3$ & - & 一 & - \\
\hline Sac & 3 & $29 \cdot 4$ & $31 \cdot 5$ & $31 \cdot 7$ & - & $33 \cdot 8$ \\
\hline Sac & 4 & $30 \cdot 0$ & $32 \cdot 2$ & $32 \cdot 5$ & 一 & $32 \cdot 2$ \\
\hline Junk c.t. & 5 & $35 \cdot 5$ & $36 \cdot 5$ & $36 \cdot 2$ & 一 & - \\
\hline Junk c.t. & 6 & $37 \cdot 6$ & $36 \cdot 8$ & $37 \cdot 2$ & - & - \\
\hline
\end{tabular}

Body (1) Probe inserted well in front of dorsal fin into a hole in the blubber. Start 11.05 h. Finish $11.08 \mathrm{~h}$

Outside body

Muscle

Muscle

$\begin{array}{lllll}1 & - & - & - & - \\ 2 & 25.5 & - & - & - \\ 3 & 26.3 & - & - & - \\ 4 & 26.6 & - & - & - \\ 5 & 30.4 & - & - & - \\ 6 & 31.6 & - & - & -\end{array}$

(2) Probe inserted just in front of dorsal fin. Start $11.09 \mathrm{~h}$. Finish 11.21 h.

$\begin{array}{llllll}\text { Outside body } & 1 & - & - & - & - \\ \text { Blubber } & 2 & - & - & - & - \\ & 3 & 27 \cdot 4 & 27 \cdot 8 & 27 \cdot 7 & 27 \cdot 9 \\ \text { Muscle } & 4 & 32 \cdot 0 & 33 \cdot 3 & 33 \cdot 5 & 33 \cdot 8 \\ \text { Muscle } & 5 & 35 \cdot 7 & 37 \cdot 8 & 38 \cdot 0 & 38 \cdot 3 \\ & 6 & 35 \cdot 3 & 37 \cdot 6 & 37 \cdot 7 & 38.4\end{array}$

Two whales gave positive results and in each instance they were positive for both nares. This adds some support to the conclusion that water is circulated through both nares but it cannot be considered conclusive because flooding of the nares at the time of death could take place.

Several tests on several other whales gave negative results in both nares. These cannot be regarded as reliable since tests applied to the outside of several whales also gave negative results. Blood or oil washing over the surface of the naris could remove traces of sea water. 


\section{APPENDIX V. HEAT TRANSFER}

Conduction of heat from the spermaceti oil of the sac into water within the right naris is very slow in the dead whale. This was tested in a dead $33 \mathrm{ft}(10.1 \mathrm{~m})$ female (no. 2139) at Durban in 1969.

The blubber was removed, the museau de singe was exposed, and the head was cut from the body. A hose was run until the water issuing from it had a steady temperature of $21.5{ }^{\circ} \mathrm{C}$ and was then inserted into the right nasopalatine opening at the rear of the skull. This opening was only about 1 in in diameter and had a fold and sphincter which made penetration by the hose difficult. After a first attempt the nozzle came out, and the weight of water already in the naris or nasofrontal sac seemed to hold it shut because, when a finger was forced in, water squirted out. Having re-inserted the hose the water was turned on and, after a brief interval, water started to squirt from the museau de singe. The rate of flow from this opening was measured by timing the filling of a 101 handbowl with a stopwatch six times during the experiment. The time taken for the first filling was $23 \mathrm{~s}$ as the naris was still filling, afterwards fillings took $20.5-21.5 \mathrm{~s}$, averaging $21.1 \mathrm{~s}$. The experiment lasted from 00.18 to $01.18 \mathrm{~h}$, during which time the water leaving the naris changed from $22.3{ }^{\circ} \mathrm{C}$ at the beginning to $21.5{ }^{\circ} \mathrm{C}$ at the end. Thus 17061 had passed through the sac in $1 \mathrm{~h}$. During this time the temperature of the spermaceti oil tissue had been taken at 5 min intervals at a position one-third of its length from the front and with the bulb of the thermometer about 6 in within the case. The temperature did not change from $31.5{ }^{\circ} \mathrm{C}$ during the hour of the experiment. The case was then cut along its length and the temperature of the spermaceti oil tissue was taken at various places along the sac length and width. These temperatures varied from 29 to $31.5{ }^{\circ} \mathrm{C}$. Some solidified spermaceti was present within an inch or two of the naris along its length and on the outside of the sac near the case, probably due to the removal of the blubber of the head. The thermometer was calibrated to within an accuracy of $0.2{ }^{\circ} \mathrm{C}$. This experiment shows that the low thermal conductivity of spermaceti oil would prevent appreciable loss of heat by conduction alone into the right naris during a dive.

\section{REFERENCES}

Alexander, R. McN., 1971. Animal Mechanics. 346 pp. London: Sidgwick \& Jackson.

Altmann, P. L. \& DitTmaR, D. S., 1968. Metabolism. 737 pp. Bethesda, Maryland: Federation of American Societies of Experimental Biology.

Beale, T., 1838. The Natural History of the Sperm Whale, 2nd ed. 393 pp. London: Jan Van Voorst.

BEDDARD, F. E., 1915. Contributions to the knowledge of the anatomy of the sperm whale (Physeter macrocephalus) based upon the examination of a young foetus. Annals of Durban Museum, 1, 107-124.

Benedict, F. G., 1938. Vital energetics. A study in comparative basal metabolism. Publications. Carnegie Institution of Washington, No. 503, 175-176.

BerzIn, A. A., 1972. The Sperm Whale. Jerusalem: Israel Program for Scientific Translations Ltd. [Transl. E. Hoz and Z. Blake.]

Caldwell, D. K., Caldwell, M. C. \& Rice, D. W., 1966. Behaviour of the sperm whale, Physeter catodon L. In Whales, Dolphins and Porpoises (ed. K. S. Norris), 789 pp. Berkeley, Los Angeles: University of California Press. 
Clarke, M. R., 1970. The function of the spermaceti organ of the sperm whale. Nature, London, 228, 873-874.

Clarke, M. R., 1976. Observation on sperm whale diving. Fournal of the Marine Biological Association of the United Kingdom, 56, 809-810.

ClARKE, M. R., 1978a. Structure and proportions of the spermaceti organ of the sperm whale. fournal of the Marine Biological Association of the United Kingdom, 58, 1-17.

Clarke, M. R., 1978b. Physical properties of spermaceti oil in the sperm whale. fournal of the Marine Biological Association of the United Kingdom, 58, 19-26.

CLARKe, M. R., 1978c. Cephalopods in the diet of sperm whales of the southern hemisphere and their bearing on sperm whale biology. 'Discovery' Reports. (In the Press.)

Clarke, R., 1954. Open boat whaling in the Azores. 'Discovery' Reports, 26, 281-354.

Denton, E. J., 1974. On the buoyancy and the lives of modern fossil cephalopods. Proceedings of the Royal Society B, 185, 273-299.

FELTS, J. L., 1966. Some functional and structural characteristics of cetacean flippers and flukes. In Whales, Dolphins and Porpoises (ed. K. S. Norris), 789 pp. Berkeley, Los Angeles: University of California Press.

Fuglister, F. C., 1960. Atlantic Ocean Atlas. 209 pp. Woods Hole, Massachusetts: Woods Hole Oceanographic Institution.

Gambell, R., 1972. Sperm whales off Durban. 'Discovery' Reports, 35, 199-358.

Gilpin-Brown, J. B., Denton, E. J. \& Clarke, M. R., 1978. On the buoyancy of oceanic squids. (In preparation.)

HeEzEn, B. C., 1957. Whales entangled in deep-sea cables. Deep-Sea Research, 4, 105-115.

Hill, A. V., 1950. The dimensions of animals and their muscular dynamics. Science Progress, 150, 209-230.

Hopkins, W. J., 1922. She Blows! And Sperm at That! 361 pp. New York: Houghton Mifflin.

Irving, L., Peyton, L. J., Bahn, C. H. \& Peterson, R. S., 1963. Regulation of temperature in fur seals. Physiological Zoölogy, 36, 275-284.

Irving, L., Scholander, P. F. \& Grinnell, S. W., 1941. The respiration of the porpoise Tursiops truncatus. Fournal of Cellular and Comparative Physiology, 17, 165-168.

KANwisher, J. \& Senft, A., 1960. Physiological measurements on a live whale. Science, New York, 131, 1379-1380.

KANWISHER, J. \& Sundnes, G., 1966. Thermal regulation in cetaceans. In Whales, Dolphins and Porpoises (ed. K. S. Norris), 789 pp. Berkeley, Los Angles: University of California Press.

KERMACK, K. A., 1948. The propulsive powers of blue and fin whales. Fournal of Experimental Biology, 25, 237-240.

KIbLER, H. H. \& BRODY, S. 1943. Growth and development with special reference to domestic animals. LVII. An index of muscular-work capacity. Research Bulletin. Missouri-agricultural Experimental Station, 367, 1-20.

KLEINENBERG, S. C. \& YABLOKOV, A. V., 1958. The morphology of the upper respiratory tract of whales. Zoologicheskii zhurnal, 37, (7), 1091-1099.

LANGE, N. A., 1967. Lange's Handbook of Chemistry. 2001 pp. London: McGraw-Hill.

LAWRENCE, B. \& SCHEvill, W. E., 1956. The functional anatomy of the delphinid nose. Bulletin of the Museum of Comparative Anatomy at Harvard College, 114, 103 pp.

LOCKYER, C., 1977. Observations on diving behaviour of the sperm whale Physeter catodon. In $A$ Voyage of Discovery (George Deacon 7oth Anniversary Volume - Supplement to Deep-Sea Research), pp. 591-609. Pergamon Press.

Malins, D. C. \& VARANasi, U., 1975. Cetacean biosonar. II. The biochemistry of lipids in acoustic tissues. In Biochemical and Biophysical Perspectives in Marine Biology, vol. 2 (ed. D. C. Malins and J. R. Sargent), pp. 273-290. London: Academic Press.

MoRRIS, R. J., 1975. The lipid structure of the spermaceti organ of the sperm whale (Physeter catodon). Deep-Sea Research, 20, 911-916.

NoRRIS, K. S., 1975. Cetacean biosonar. I. Anatomical and behavioural studies. In Biochemical and Biophysical Perspectives in Marine Biology, vol. 2 (ed. D. C. Malins and J. R. Sargent), pp. 215-236. London: Academic Press.

NoRRIS, K. S. \& HARVEY, G. W., 1972. A theory for the function of the spermaceti organ of the sperm whale. In Animal Orientation and Navigation (ed. S. R. Galler, K. Schmidt-Koenig, G. J. Jacobs and R. E. Belleville), 262 pp. NASA Special Publication. 
OMURA, H., 1950. On the body weight of the sperm and sei whales located in the adjacent waters of Japan. Scientific Reports of the Whales Research Institute, 4, 1-13.

PARRY, D. A., 1949. The structure of whale blubber and its thermal properties. Quarterly fournal of Microscopical Science, 90, 13-26.

Pouchet, G. \& Beauregard, H., 1889. Recherches sur le cachelot: anatomie I-V. Nouvelles archives du Muséum d'histoire naturelle, Paris, 1889 (3), 1-96.

RAVEN, H. C. \& GREGoRY, W. K., 1933. The spermaceti organ and nasal passages of the sperm whale (Physeter catodon) and other odontocetes. American Museum Novitates, 677, 1-18.

Ridgway, S. H., SCronce, B. L. \& Kanwisher, J., 1967. Respiration and deep diving in the bottlenose porpoise. Science, New York, 166 (3912), 1651-1653.

RIDGWAy, S. H., 1970. Buoyancy regulation in deep diving whales. Nature, London, 232, 133-134.

SChenkKan, E. J. \& PuRves, P. E., 1973. The comparative anatomy of the nasal tract and the function of the spermaceti organ in the Physeteridae (Mammalia, Odontoceti). Bijdragen tot de dierkunde, 43, 92-112.

SCHOLANDER, P. F., 1940. Experimental investigations on the respiratory function in diving mammals and birds. Hvalrådets skrifter, 22, 1-131.

Scoresby, W., 1820. An Account of the Arctic Regions, 2 vols. Edinburgh.

SERGEANT, D. E., 1969. Feeding rates of cetacea. Fiskeridirektoratets Skrifter. Serie Havundersokelser, 15, 246-258.

SliJPER, E. J., 1962. Whales. 475 pp. London: Hutchinson. [Transl. from Dutch by A. J. Pomerans.]

Tomilin, A. G., 1947. A new look at the spouting of whales. Doklady Akademii nauk SSSR, 55 (2).

TownsEND, C. H., 1932. The distribution of certain whales as shown by logbook records of American whaleships. Zoologica (New York), 19, 1-50.

Watkins, W. A. \& Schevill, W. E., 1972. Sperm whales (Physeter catodon) react to pingers. Deep-Sea Research, 22, 123-129.

WATKINS, W. A. \& SCHEviLl, W. E., 1977. Spatial distribution of Physeter catodon (sperm whales) underwater. Deep-Sea Research, 24, 693-699.

Wust, G., 1932. Das ozeanographische Beobachtungsmaterial. Wissenschaftliche Ergebnisse der Deutschen Atlantischen Expedition auf dem Forschungs- und Vermessungsschiff 'Meteor', $1925-27,4(2), 1-290$. 